\title{
Acumulación, regulación, ondas y estrategias en las luchas del trabajo
}

\section{Andrés Piqueras*}

\begin{abstract}
Resumen: El artículo trata de realizar una introducción diacrónica de las relaciones Capital/Trabajo, con epicentro de referencia en las sociedades centrales, combinando las aportaciones de ciertas escuelas regulacionistas con las de las ondas largas del capitalismo y las que incluyen ciclos de combatividad del Trabajo y ofensivas o contraofensivas estratégicas del Capital, desde la estrategia investigadora del materialismo dialéctico. Su fin es servir de apoyo a modelos analíticos sobre la combatividad del Trabajo combinada con las dinámicas de acumulación y regulación del Capital, que sean capaces de vislumbrar las posibilidades de reconstitución de la agencialidad política del Trabajo en la actualidad, y acompañarlas.
\end{abstract}

obrero

Palabras clave: combatividad, conciencia, Trabajo, Capital, Movimiento

\section{Accumulation, regulation, waves and strategies in the working realm fights}

Summary: The article intends to realize a diachronic introduction of the relations Capital/Work, with epicenter of reference in central societies, combining the contributions of certain regulationists schools with those of the long waves of Capitalism and those that include cycles of Work combativity and offensives or strategic counter-offensives of Capital, from the investigating strategy of dialectic materialism. Its aim is to serve as support to analytical models on Work combativity combined with dynamics of accumulation and regulation of Capital, that may be able to glimpse the possibilities of reconstruction of the political agentiality of Work today, and accompany its process.

Key words: combativity, consciousness, Work, Capital, Workers movement

\section{Acumulação, regulação, ondas e estratégias nas lutas do trabalho}

Resumo: O artigo trata de realizar uma introdução diacrónica das relações Capital/Trabalho, com epicentro de referência nas sociedades centrais, combinando as contribuições de certas escolas regulacionistas com as das ondas longas do capitalismo e as que incluem ciclos de combatividade do Trabalho e ofensivas ou contraofensivas estratégicas do Capital, desde a estratégia investigadora do materialismo dialéctico. Seu fim é servir de apoio a modelos analíticos sobre a combatividad do Trabalho combinada com as dinâmicas de acumulação e regulação do Capital, que sejam capazes de vislumbrar as possibilidades de reconstitução da

*Universidad Jaume I de Castellón, Castellón, España. Email: piqueraa@fis.uji.es 
agencialidade política do Trabalho na actualidade, e acompanhá-las.

Palavras-chave: combatividade, consciência, Trabalho, Capital, Movimento operário

Recibido: 07.10.2009

Aceptado: 26.10.2009

$* * *$

\section{Introducción}

El objetivo de las reflexiones que sirven de introducción al presente número colectivo es contribuir a la explicación de la combatividad del Trabajo e intentar establecer qué papel juegan en ella los diferentes procesos asociados a la dinámica de acumulación-regulación del Capital, así como los vinculados a la propia capacidad organizativa y reivindicativa del Trabajo ${ }^{1} y$, dentro de ésta, la relativa importancia de la conciencia.

La combatividad explícita del Trabajo, desde que se constituye como sujeto histórico, ha experimentado ciertamente una alta discontinuidad o momentos de auge y decadencia que algunas escuelas de la ciencia social han intentado secuenciar en virtud de diferentes criterios. Una de las más potentes líneas de explicación sobre esa discontinuidad del accionar político del Trabajo es la que ha vinculado éste a las recurrentes crisis estructurales del capitalismo y las correspondientes estrategias del Capital para sobreponerse a las mismas.

De este esfuerzo analítico se deriva la recurrencia a las ondas largas, que hacen referencia a periodos de ascendencia de la acumulación capitalista, de unos 25 años, tras los cuales se ralentiza esa acumulación hasta que un determinado modelo de acumulación entra en crisis y es sustituido por otro que ya presentaba rasgos latentes en el anterior, sin que ello quiera decir que las formas del modelo en crisis desaparezcan en el nuevo

\footnotetext{
${ }^{1}$ Sobre la explicación de los conceptos Capital y Trabajo, con mayúsculas, como sujetos históricos, ver Piqueras (2002) y en esta misma revista, más sucintamente, Piqueras (2005). Resumimos aquí muy brevemente que el Capital con mayúsculas hace referencia a la parte agencial del capital con minúsculas, y está integrado por quienes viven de explotar el trabajo ajeno sin tener que autoexplotarse a sí mismos, principales beneficiarios del sistema capitalista y por tanto interesados en sustentarlo y reproducirlo. Trabajo, con mayúsculas, comprende a quienes tienen que recurrir a trabajar para otros o bien autoexplotarse (lo que a la postre supone trabajar para terceros) como único o principal medio de garantizar su subsistencia. Es obvio que entre unos y otros caben situaciones intermedias, pero no las entraremos a analizar aquí por su poca significación relativa para los objetivos de este estudio. Con el concepto de Trabajo no tratamos de simplificar la heterogeneidad de las clases subordinadas, ni aparentar una similitud de sus condiciones de vida, ni mucho menos (ver nota 4), sino de dar un sentido terminológico universal a su común relación de explotad@sautoexplotad@s o explotables en cuanto que ya están proletarizados, es decir, desprovistos de medios de producción para asegurarse la supervivencia.
} 
modelo, sino que están presentes en él aunque no de manera hegemónica² .

Si bien es cierto que con ello pareciera que el presente análisis estuviese ubicado en el ámbito de las escuelas regulacionistas ${ }^{3}$, difiere de éstas en cuanto que aquí está desprovisto del aspecto más estático que tales escuelas han dado a la regulación, ya que mediante ella han tendido a ver distintos órdenes sociales legitimados y relativamente estables que se suceden históricamente cuando se agota su capacidad de generar acumulación y aceptación o colaboración generalizada. Por el contrario, nosotros apreciamos la "regulación" en la connotación que más pudiera hacer honor a la que entendemos fue la elaboración marxiana, como el conjunto de políticas, intervenciones públicas, formas institucionales y de pensamiento, normas, dispositivos de socialización y medios de construcción de la realidad y de legitimación, hábitos de comportamiento y el conjunto de subjetividades generadas que acompañan a un determinado régimen de acumulación, pero que están sujetos a permanente fracturas, contradicciones y contraconstrucciones internas. Por ello ese entramado de factores constitu-

\footnotetext{
${ }^{2}$ Las ondas largas son concebidas como resultado de una tendencia endógena del capital y del sistema que genera, el capitalismo, a que la composición orgánica del capital sea periódicamente y a pesar de diversos factores contratendenciales, decisiva a la hora de provocar una caída de la tasa de ganancia. Caída que arrastra un conjunto de consecuencias y procesos que dan como resultado ciertas "crisis", que pueden ir desde la desaceleración a la recesión y, en consecuencia, desde meros ajustes económicos y sociopolíticos, a profundas reestructuraciones en unos y otros ámbitos. Son estas últimas las que han conducido a numerosos autores marxistas a aceptar ondas largas en el desarrollo capitalista. Dos siglos no es suficiente tiempo como para tener seguridades históricas, y en la práctica no está nada claro el conjunto de atribuciones que se hacen a esas 'ondas' (ver al final nota 49). No obstante, lo que parece constatado es que el sistema capitalista tiene esa inevitable tendencia a la "crisis" de acumulación, o por decirlo de otra manera, es el único sistema histórico en el que la riqueza constituye un problema. Cómo contrarrestar esa tendencia e iniciar nuevos ciclos de acumulación tras la "destrucción constructiva" de cada ciclo, ha sido desde el principio una obligación sistémica del Capital en cuanto que sujeto histórico. Como quiera que, por tanto, ciertas de aquellas consideraciones implícitas en los análisis de las ondas largas pueden ser de interés para nuestro propósito, las hacemos servir de referencia en el presente estudio, sin que ello quiera decir que aquí se defienda que los ciclos puedan perpetuarse indefinidamente. Antes bien, partimos de la premisa de que las crisis tienden a ser exponencialmente más graves cada vez, y que tienden en el presente a cortocircuitar a medio plazo las posibilidades de supervivencia del sistema capitalista.

${ }^{3}$ Estas teorizaciones intentan explicar la paradoja de por qué el capitalismo tiene tendencias hacia la crisis, el cambio y la inestabilidad, que son contrarrestadas por su habilidad adaptativa a las mismas, a través de un dúctil entramado institucional-normativo-ideológico-subjetivo. La teoría está basada en dos conceptos clave, los regímenes de acumulación o formas de organizar la producción y el consumo (fordismo, post-fordismo, etc...) y los modos de regulación, que se refieren a las instancias sociopolíticas, jurídicas e ideológicas que se retroalimentan con ese régimen de acumulación. De acuerdo con las teorías de la regulación, todo régimen de acumulación alcanzará un punto de crisis en el cual el modo de regulación no podrá sostenerse, y la sociedad estará forzada a encontrar nuevas reglas y normas, pergeñando un nuevo régimen de acumulación, que estará vigente hasta que desarrolle su propia crisis, y así sucesivamente.
} 
ye un (intento de) modo de regulación de un determinado régimen de acumulación, pero en conjunto se hallan en permanente tensión "desreguladora” provocada por los numerosos agentes que les dan vida. Por eso, y por lo expuesto en nota 2, la combinación que aquí presentamos entre "regulación” y "ondas largas" no se interfiere con la que pensamos es una tendencia del capitalismo a acelerar sus propios límites.

Cabe precisar, además, que aquí entendemos por modelo de acumulación la combinación resultante de un régimen de acumulación y del modo de regulación que le es anejo.

Respecto a la intersección entre regulaciones y ondas largas, las hipótesis de partida suelen proponer que en una fase u onda larga ascendente el Capital cuenta con suficientes recursos como para estar más abierto a, o incluso promover el reformismo social y, en general, la integración del Trabajo, a través tanto de la cooptación como del consenso, merced a la secuencia que instaura: incremento tasa de ganancia - acentuación del consumo - aumento de lo salarios reales - complicidad de la población.

Se produce por tanto, en estas fases, una inclinación a una parcial desmercantilización de la mercancía fuerza de trabajo. Con ello se acrecienta el poder social de negociación del Trabajo y disminuye la rentabilidad general del capital.

En las subsecuentes fases descendentes se desata un mayor descontento pero al tiempo disminución del poder social de negociación del Trabajo, que van de la mano de mayores niveles de represión y conflicto. Se incrementa la mercantilización de la mercancía fuerza de trabajo y una combinación de la que se ha llamado “conflictividad polanyana y marxiana”, como a continuación se explica.

La premisa general es que cualquier salida hacia adelante en orden a superar una de sus fases de crisis requiere para el Capital una ofensiva general contra el Trabajo y sus logros históricos, en una intervención respecto a la lucha de clases (en realidad luchas de clase ${ }^{4}$ ) que ha ido realizándose de forma cada vez más planificada. Sin embargo, como a nadie se le escapa, esas luchas de clase conllevan también una dimensión interna,

\footnotetext{
${ }^{4}$ La relación de clase es la que se produce cuando unos seres humanos se apropian del hacer y de lo hecho por otros (quienes son expropiados de su hacer y de lo hecho). Es decir, media entre ellos un proceso de explotación. Lo que se traduce también en una usurpación de oportunidades de vida de los últimos por los primeros. Las oportunidades de vida hacen referencia al diferente acceso a los recursos, prestigio y poder que tienen los seres humanos dentro de una determinada sociedad. Condicionando, por tanto, la capacidad de acción y decisión de unas u otras personas y, en conjunto, sus posibilidades de autonomía. La lucha de clase es la que se produce en torno al proceso de explotación o relación de clase. Como puede apreciarse, intentamos complementar con estas precisiones las aportaciones del marxismo clásico con las del de inspiración más weberiana (según autores como Wright, o, salvando todas las distancias, incluso Roemer).
} 
intracapitalista, por la que unos capitales eliminan de la competencia a otros, los menos “competitivos” (cuya menor productividad les relega por debajo de la media de la tasa de ganancia que se consigue en una determinada sociedad), produciéndose una tendencial dinámica de concentración y centralización del capital.

Dentro de esta línea de investigación destaca, entre otras, la aportación de Beverly Silver, quien sostiene que la mercancía fuerza de trabajo no puede ser abandonada totalmente al mercado autorregulado sin la intervención de agentes institucionales y muy especialmente del Estado (del mismo modo que la economía capitalista no podría funcionar sin éste o alguna otra entidad que hiciera sus veces). Esto produce permanentes oscilaciones entre la mercantilización y la desmercantilización de la fuerza de trabajo. La mayor mercantilización o deterioro de la condición salarial provoca la descomposición y por tanto resistencia de las capas del Trabajo que se habían acomodado (conflictividad de tipo polanyano) y al tiempo la formación y por tanto insurgencia de nuevas capas proletarizadas o que han experimentado drásticos cambios en su condición de asalariazación, lo que implica nuevas agencias y nodos de conflicto, nuevas reivindicaciones y formas de lucha (conflictividad de tipo marxiano) (Silver, 2005: 31-33)

En cambio, cuando disminuye la mercantilización de la fuerza de trabajo aumenta el poder general de negociación del Trabajo, pero también la división entre el mismo, mediante identificaciones o identidades (de estatus o también de competencia laboral) fuera de la identidad de clase, que resultan mecanismos de autoprotección o distinción de las capas más altas del Trabajo. Estas identificaciones se hacen valer a menudo después, en las fases descendentes, como blindaje contra los sectores más precarizados de la fuerza de trabajo, para preservar ciertas garantías de los estratos más altos.

En definitiva, las hipótesis principales que se han manejado hasta hoy tienden a concordar en que en las fases de ascenso se acentúa paulatinamente la organización y fortaleza del Trabajo, pero de forma integrada (reformista). En las fases de crisis o de ralentización del crecimiento de la ganancia, disminuye la posición objetiva del Trabajo para influir protagonísticamente en el decurso del sistema capitalista, acentuándose por el contrario la dinámica de pugna intraCapital como motor de los cambios $\mathrm{y}$, en definitiva, como agencia conductora del sistema (ver al respecto, por ejemplo, las obras de Robert Brenner -y en especial Brenner, 2006-). Pero por contra y aun así, las más concienciadas minorías del Trabajo (vanguardias) se hacen más rupturistas, preparando la posterior agudización de la lucha de clase, que encuentra más nutrientes según se deterioran las condiciones del conjunto del Trabajo, y con ellas, las de legitimidad general del sistema, pues en su búsqueda de salidas a sus crisis, el Capital debe congeniar el aumento de la tasa de plusvalía con la acentuación de la tasa de explotación y el consiguiente deterioro de las condiciones laborales y de distribución de la riqueza social. 
No obstante, tales procesos no son ineluctables; esta última tendencia queda supeditada también al propio desarrollo del Trabajo como sujeto en cada fase histórica y a sus plasmaciones organizativas e ideológicas. Factores que tampoco son independientes de la propia evolución del sistema capitalista y de la conformación del Capital como sujeto histórico. Unos y otros procesos están entrelazados dialécticamente.

Una de los desafíos intelectuales del momento actual es explicar las razones por las cuales si el movimiento obrero tuvo un gran respaldo popular o comunitario más allá de los centros laborales, en los momentos de resistencia generalizada, cuando el Trabajo se rehacía de la dureza de la agresión de clase en las fases descendentes de la acumulación de capital, hoy esto no se da, y porqué se produce la drástica decadencia política de la fuerza de trabajo y también la dilución general de las fuerzas del Trabajo ${ }^{5}$.

Pensamos que es útil para explicárnoslo hacer un repaso histórico de la propia agencialidad del Capital o de las estrategias que éste ha desplegado contra el Trabajo, siguiendo la inspiración de analistas como Silver, ya citada, pero también de otros como David Harvey y especialmente de un marxista clásico como Ernest Mandel, probablemente quien mejor haya complementado sociopolíticamente el análisis económico de las ondas largas del capitalismo.

La línea de investigación que lleva a desentrañar la vertiente estratégica del Capital contra el Trabajo advierte de que las condiciones y posibilidades organizativas de la fuerza del trabajo están relacionadas, además de con los procesos de acumulación capitalista, al menos con dos importantes conjuntos de factores:

1. La política mundial o sistémica que ha ido dándose a lo largo del capitalismo histórico, con sus oscilaciones de rivalidades y hegemonías intercapitalistas.

\footnotetext{
${ }^{5}$ Es prácticamente un lugar común en los análisis marxistas advertir que vivimos en la actualidad en un tipo de sociedad mundial profundamente marcado por el dominio del Capital. La crisis estructural de sobreproducción de éste, que ya tiende a enquistarse, encuentra al Trabajo en un estado de total falta de preparación subjetiva y por tanto política, patéticamente desorganizado y falto de referentes ideológicos alternativos. Al fetichismo inherente a las relaciones sociales de producción capitalista, cabría sumar hoy la gran alienación de lo social (la des-socialidad), esto es, el desprecio por lo colectivo y el repliegue en lo individual, el fetiche del individuo autárquico opuesto a la inherente constitución social de los seres humanos. Del fetichismo del capital como ente con vida propia, pasamos así al fetichismo de lo privado como motor de la riqueza colectiva. Esto significa ver el mundo exclusivamente a través de los lentes del capital en cuanto que relación social, con la ideología inmediata o espontánea que de ello se deriva. Cuando los subordinados se identifican así con los supraordinados en un mismo orden social, estos últimos precisan cada vez menos de los dispositivos de violencia explícita y su dominio se hace más profundo, más hegemónico.
} 
2. Las políticas económicas del Capital para disminuir el poder de negociación del Trabajo, que pasan principalmente por 4 tipos de desplazamiento:

- Desplazamiento espacial y temporal del capital [Movilidad]

- Desplazamiento tecnológico-organizativo del capital [Innovaciónplanificación]

- Desplazamiento del capital hacia nuevas líneas de producción e industrias más rentables, con nuevas formas o elementos dominantes de producción [Neoproducción] ciarización]

- Desplazamiento del capital fuera de la producción [Finan-

Entre unos y otros de estos procesos, el Capital ha estado siempre urgido por una delicada y difícil compensación entre las crisis de rentabilidad y las de legitimidad, debiendo enfrentar constantemente las fuentes del poder del Trabajo como productor (como clase trabajadora) y como reproductor social, en un permanente intento de debilitarlas. Es por eso mismo que ineludiblemente una parte importante de la dinámica del propio Capital está condicionada por el Trabajo.

Sin embargo, son muchos los interrogantes que plantean la enorme heterogeneidad de las realidades del Trabajo y su alta segmentación y plurifragmentación respecto a su capacidad de incidencia consciente (¿Coordinada?), como seres humanos iguales, en el devenir de un sistema que no está hecho en su beneficio.

Quedan demasiadas preguntas sin respuesta convincente todavía. Así por ejemplo, ¿ existen pautas recurrentes o contrastables entre la acción de clase y la conciencia colectiva política?, ¿bajo qué circunstancias es susceptible de activarse más esta última? ¿Se produce una relación inversa entre poder social de negociación y militancia política? ¿Por qué se suman hoy pérdida de poder social de negociación y también de militancia, elevación de la mercantilización de la fuerza de trabajo y falta de respuesta del Trabajo?

Para sopesar las respuestas hemos de tener en cuenta el dilema o aparente callejón sin salida del que el marxismo (al igual que el resto de praxis políticas) no ha logrado salir todavía. Y es que, si se afina un poco y contrariamente a las tan consabidas como poco informadas críticas de economicismo contra él, el materialismo dialéctico hace recaer, a la postre, todo el peso de la transformación social en un factor tan inconcreto, inestable y abierto a la indeterminación y disparidad, como es la conciencia ${ }^{6}$.

\footnotetext{
${ }^{6}$ Si la conciencia (que la ciencia social en los últimos tiempos ha tendido a entender también como reflexividad) de las partes (los seres humanos) no puede nunca abarcar el todo (léase en este caso, el sistema social, biológico y ambiental en que están inmersos) y si cada intervención consciente genera consecuencias no previstas y/o no queridas y también procesos inconscientes, ya no es sólo que la conciencia sea ciega a su propio inconsciente, sino que es inconsciente de muchos de los niveles sistémicos que afectan al ser humano. Enton-
} 
Por eso, la cuestión es más peliaguda aún que la presentada en el clásico problema que atañe al núcleo de la elaboración marxiana cuando predica que sin conciencia no hay combatividad antagónica, lo que inmediatamente remite a la paradoja de que si la conciencia es parte de unas determinadas condiciones materiales de existencia, ¿cómo alcanzar entonces la conciencia política ${ }^{7}$ en condiciones materiales de existencia que la dificultan sobremanera? En pocas palabras, nuestras dudas ante la conciencia como entidad colectiva planificadora y autocorrectora (mediante la cual los seres humanos se dotan de una especie de teleología común), se suman a la gran incógnita no despejada que planteó el marxismo, ¿cómo de la nada devenir todo?

Esto es, ¿cómo adquirir colectivamente, de forma durable, en el caso de grandes contingentes de población, esa conciencia política?

La solución a través de la inculcación externa, [gracias a las "vanguardias” y sobre todo al Partido (como intelectual colectivo)], aunque nos ha dejado abierta una importante vía de posibilidad, no ha mostrado hasta hoy capacidad de realización estable para tamaños considerables de poblaciones (cuanto menos si hablamos del conjunto de la humanidad).

Si bien es cierto que las paradojas sólo pueden ser resueltas en las praxis, estas últimas, entendidas para nuestro propósito como desarrollos históricos agenciales del Trabajo, nos han dejado no pocas dudas ${ }^{8}$.

ces la pregunta sería si la conciencia permitiría a las sociedades humanas autoprogramarse y escapar así a "las azarosas alteraciones de estado características del resto de sistemas complejos autoorganziadores” (García, 1995).

${ }^{7}$ Aquella que es capaz de comprender los condicionamientos estructurales en que se desenvuelven las propias condiciones de vida (individuales y colectivas) y posibilita actuar para incidir sobre ellas.

${ }^{8}$ El problema de algunas de esas praxis ha radicado en la reificación de la clase. La clase es una construcción teórica que designa las posiciones comunes de unos u otros individuos en la relación de clase (ver nota 4). Pero esa posición común no implica condiciones iguales de vida, ni siquiera a menudo, parecidas, menos aún cuando hablamos del proletariado mundial. Esas diferentes condiciones y oportunidades de vida, llevan emparejadas por lógica materialista, dispares condiciones de conciencia. Es decir, que las clases sociales no son entidades agenciales de conciencia colectiva. Obviando este hecho contrastable, ciertas interpretaciones del marxismo se empeñaron históricamente en hacer de la clase una suerte de ente con vida propia, cohesionado y cohesionador, unificador de voluntades y homogenenizador de conciencias. De esta manera, aunque sólo el proletariado, como condición generalizada humana que expande el capitalismo, puede ser "el sepulturero" de la actual clase dominante, el dilema es que éste no ejercerá de tal sino hasta el momento en que adquiera la suficiente maduración de conciencia o conciencia capaz de trascender su inmediatez subjetiva, nutrida en y por el orden capitalista. Y así ya estamos otra vez en el comienzo, ¿quedaría por tanto la "necesidad histórica" de lo que tiene que ser supeditada a este indeterminado factor de segundo orden, o bien no será tan "indeterminado" dado que el propio capitalismo generará las condiciones que faciliten esa conciencia a través de la combinación del desarrollo de las fuerzas productivas y sus crecientes crisis de acumulación y 
A pesar de todo ello, la conciencia se ha mostrado palmariamente no sólo como un factor imprescindible para la agencialidad colectiva, sino también de enorme potencialidad constructiva y capacidad instituyente, especialmente cuando se convierte en identidad. Y aquí radica uno de los principales pivotes del proceso de humanización. Crea realidad y genera subjetividades con respecto al desarrollo de unas determinadas fuerzas productivas dentro de un orden socioeconómico. Líquido amniótico que se retroalimenta con un determinado orden social, parece ser que en él se enmarca el alfa y el omega de nuestros principales interrogantes: ¿cómo generar conciencia a contrapelo de ese orden? Esto es, ¿cómo hacer extensivo el salto político que es capaz de entender los entramados estructurales que subyacen a las propias condiciones de existencia y actuar para transformar unos y otras, teniendo en cuenta que aun en los momentos álgidos de movilización del Trabajo sólo unas minorías tuvieron conciencia política, esto es transmediata, más allá de sus vías de posibilidad individual inmediata?

Las respuestas que podemos proporcionar y los pasos que podemos dar aquí son mucho más modestos, y están centrados en el análisis de la combatividad histórica del Trabajo. Sabemos al menos, en este sentido, que con la evolución del capitalismo se ha dado una constante tensión entre la tendencia por parte de los sujetos del Capital a rebajar el poder de negociación social del Trabajo en el mercado laboral, y el incremento involuntario de ese poder en el lugar de trabajo (mediante procesos que van anejos a su imposibilidad de evitar a medio plazo la socialización objetiva de la

deterioro de condiciones de vida? ¿Salimos así realmente del postulado kautskiano de inevitabilidad, la encerrona en que quedó atrapada la II Internacional? Pero donde más se lleva al extremo la confianza en la conciencia como factor determinante es en la resolución anarquista, para la que el resultado de la acción revolucionaria anticapitalista está más desligado aún de las condiciones socioeconómicas o materiales, siendo producto directo de una especie de voluntad colectiva, sin etapa de transición ni entidades de coacción sobre la actual clase dominante, sino por una especie de "consenso social inspirado en la supuesta tendencia natural de los seres humanos genéricos a la cooperación en pequeña escala”. Como si las clases no existieran y como si los intereses de todos fueran coincidentes. Enfrentando la pequeña propiedad privada de los medios de producción a la propiedad socializada de los mismos, proclaman que los pequeños grupos de individuos pueden ser organizados de tal forma que queden eliminados los antagonismos económicos por la tendencia natural de los seres humanos a la cooperación. Y esto vale para sociedades enteras a escala mundial. La actual ola movimientista recibe de pleno la influencia anarquista, y asume hasta el extremo esa fe inquebrantable en la conciencia, de manera que con demasiada frecuencia se pretende que de los pequeños grupos e incluso de las pequeñas acciones de cada quién, se pueda pasar a los contagios masivos, transformadores. Sin preocuparse apenas, no ya sólo por las insoslayables condiciones materiales de vida que impone un determinado sistema económico, sino tampoco, casi nunca, por la organización y planificación táctico-estratégica, cuánto menos por enfrentar el principal Poder en las sociedades capitalistas, el poder de clase (que pone a su servicio todo el resto de poderes y desigualdades). Desconsiderando, así, entre otras muchas cosas, el control oligopólico de los medios de socialización y difusión ideológica, pero también de la fuerza, que tiene el Capital. 
producción $^{9}$-ver Silver, 2005-). Es por eso que este desajuste en la dominación ha venido intentando contrarrestarse de forma planificada por parte del Capital a partir de los años 90 del siglo XX, para dejar al Trabajo cada vez más inerme en ambas vertientes.

Puede convenirse también que hay pocas posibilidades de emancipación del Trabajo como sujeto independiente mientras no sea capaz de recuperar o rehacer su propio proyecto histórico, no subordinado, ni en tanto que no se ejercite en la dirección de la sociedad (es decir, mientras no tenga experiencias exitosas de supresión de las instituciones rectoras del Capital).

No hay que olvidar que los agentes que son los principales beneficiarios e impulsores de cada sistema son los que le comandan. En el capitalismo el Trabajo siempre es un factor y también un agente subordinado al Capital. Sin embargo, se trata de un agente subordinado que ha sido capaz de idear ya una sociedad alternativa y de proporcionar, por tanto, a amplios sectores de la humanidad explotada la posibilidad de no ser al tiempo dominada $^{10}$.

Por eso la actual ofensiva del Capital combina las disposiciones "técnicas” de desplazamiento antes vistas, con la batalla ideológica e incluso cultural, para desterrar la conciencia de clase, y con ello la de las propias clases sociales y sus encontrados intereses (en virtud de una especie de sociedad civil universal en la que el diálogo y la convivencia serían los principales componentes o, al menos, sus más deseables objetivos; una supuesta amalgama de intereses que tendrían todos cabida y representación dentro de una tan hipotética como fantasmagórica ciudadanía). Todo ello combinado con una erradicación de la memoria histórica, y de la palabra o narración alternativa, en orden a impedir el reconocimiento de las conquistas del Trabajo y de eliminar de su horizonte su más importante proyección a corto plazo: el socialismo (como sociedad en transición a un mundo sin clases sociales, que constituyó el referente de vida para amplios sectores de la humanidad durante los siglos XIX y XX).

Así pues, lo que sigue es una breve introducción diacrónica de las relaciones Capital/Trabajo, con epicentro de referencia en las sociedades centrales, que pretende combinar las aportaciones de ciertas escuelas regulacionistas, con las de las ondas largas del capitalismo y las que incluyen ciclos de combatividad del Trabajo y ofensivas o contraofensivas estratégicas del Capital, desde la estrategia analítica del materialismo dialéc-

\footnotetext{
${ }^{9}$ Entendiéndose por ella el crecimiento de la coordinación, la integración y la interdependencia técnicas en la producción, por medio de las cuales el capitalismo genera crecientemente negación del trabajo privado y la producción privada de las cuales ha nacido, primero dentro de las fábricas, después dentro de un número de unidades de producción y ramas de la industria y, finalmente, entre diversos países.

${ }^{10}$ A través de la conciencia de clase sectores de la humanidad sometidos a una forzada explotación cuantitativa (extracción de plusvalor) han rechazado y rechazan la explotación cualitativa (colaboración con, y aceptación de esta relación de clase).
} 
tico. Su fin es aportar algo de luz a la situación y perspectivas actuales de las fuerzas del Trabajo en el sistema capitalista mundial ${ }^{11}$.

\section{La combatividad del Trabajo. Entre las ondas y las estrategias}

El Trabajo da origen al movimiento obrero $(\mathrm{MO})^{12}$ en la fase en que las relaciones sociales de producción capitalistas se hacen hegemónicas en algunas sociedades europeas a través del acelerado desarrollo del capital productivo-industrial [nacimiento propiamente del sistema socioeconómico que conocemos como Capitalismo (en su expresión de capital industrial o maduro)]. La primera fase ascendente de este sistema ha solido ser acotada entre dos fechas simbólicas: 1789 (revolución francesa) y 1848 (primeros levantamientos generalizados del Trabajo en Europa como clase, en cuanto que sujeto diferenciado de la burguesía ${ }^{13}$ ).

1. El primer modelo o régimen de acumulación capitalista que protagoniza ese lapsus, el de "la revolución industrial», se sustenta en la competencia generalizada entre capitales (“capitalismo de libre competencia”) y es de carácter netamente extensivo, llevando a cabo la conversión de la producción manufacturera en producción fabril mecanizada, e introduciendo la maquinaria en las ramas textil y metalúrgica. Logra también la independización energética respecto del agua, mediante la máquina de vapor y la utilización del carbón. Se da en un contexto netamente autoritario, en el que la proletarización de los seres humanos comienza a ser regulada social, política y jurídicamente, y en el que el proletariado pugna por formar parte de la ciudadanía.

\footnotetext{
${ }^{11}$ Adviértase que las periodizaciones que se realizan en la Ciencia Social, son útiles a posteriori, dado que tienen el valor de aumentar la comprensión de lo sucedido, siempre y cuando no se tomen como compartimentos estanco objetivados, sino como claves de un continuum histórico trazado por la intervención y lucha de actores y sujetos sociales dentro de cambiantes coordenadas socioeconómicas. Son por tanto ajenas a cualquier interpretación determinista, ni hacia el pasado ni hacia el futuro, pues no hay nada en la historia que dictamine obligatoriamente que los procesos sean, hayan sido o vayan a ser así. El desarrollo del capitalismo, como de cualquier otro sistema, está constituido socialmente, lo que quiere decir que no es lineal ni evolutivo. Está sujeto a la creatividad social y a la conjunción de circunstancias (muchas de ellas insospechadas para los propios actores) que le direccionan, y cuyas interacciones abren cauces imprevistos. Por ello mismo el resultado de las luchas sociales, de la lucha de clase, permanece siempre abierto, por más que, eso sí, se puedan apuntar sus tendencias.

${ }^{12}$ El movimiento obrero dará vida en adelante a una parte siempre minoritaria pero más o menos relevante, según los distintos momentos históricos, de la clase obrera como la parte del Trabajo que le dio a éste constitución de sujeto.

${ }^{13}$ Hasta ese momento los levantamientos propios de la lucha de clases habían unido tan pasajera como superficialmente a la burguesía con el proletariado y otros sectores del Trabajo contra la nobleza.
} 
Este modelo trae consigo la exacerbación de la división capitalista entre trabajo manual y trabajo intelectual, amparada en lo que se ha llamado sustracción de la destreza o del conocimiento obrero (una acentuación de la división compleja del trabajo, que se traduce en una creciente pérdida por parte de los trabajadores de sus habilidades técnicas, convirtiéndose cada vez más en apéndices humanos de la gran maquinaria industrial).

Es la subsunción real del Trabajo al Capital. Esto significa que las posibilidades de vida de la población concebida como fuerza de trabajo, esto es como una mercancía que se compra y vende, quedan supeditadas por tanto a la reproducción del propio capital y a las condiciones capitalistas de producción (debido no sólo a la pérdida de los medios de producción sino a la inserción en el proceso productivo del capital, bajo la forma de organización capitalista). Como quiera que los seres humanos se constituyan en parte vital del metabolismo del capital, dependiendo para su vida del movimiento reproductor de éste, sus formas de conciencia y de visión del mundo quedarán también supeditadas a aquella reproducción (la mente queda supeditada al organismo en el que cobra vida).

En esta fase se da la plena alienación del Trabajo (o pérdida de la capacidad de autonomía y autogestión del Trabajo), a través de su enajenamiento con respecto del conjunto del proceso productivo.

La inclusión del mundo artesanal en el proletariado y la formación de una jerarquía científico-técnica se compaginan con la formación de una burocracia política.

Con el constante desarrollo de los medios de producción como motor de la economía se agudiza la competencia generalizada entre capitales productivos individuales. Se pone en marcha la acumulación primitiva de capital a gran escala, mediante la obtención de plusvalía absoluta. Lo que quiere decir que la ganancia en la competencia entre capitales individuales se obtiene sobre todo a través del:

- el incremento de la jornada de trabajo (el conjunto de la población trabaja más horas que nunca en la historia);

- la incorporación creciente de masas de población (hombres, mujeres, niñas y niños) al proceso productivo (incremento de la proletarización de seres humanos); $\mathrm{y}$

- el descenso de los salarios al mínimo posible (el incremento productividad generaba un descenso del valor de los precios de los productos básicos, lo que permitía la bajada también de los salarios -por debajo incluso del valor de reproducción de la fuerza de trabajo, lo que quiere decir que ésta se reproduce en conjunto, como masa proletarizada, pero no individual ni familiarmente).

- Esto significa la creación de un enorme ejército de reserva (campesinado convertido en proletario) y la pauperización obrera absoluta.

Sin embargo, al generalizarse estas condiciones de explotación en 
Inglaterra a finales del siglo XVIII, se eliminan las ventajas competitivas (o lo que es lo mismo, desciende la tasa de ganancia en las empresas líderes), lo que acarrea la necesidad de otra fuente de ganancia más intensiva. Ésta vendría a través de la mecanización. Con ella la tecnología se convertiría en el principal factor de competencia. Y esa tecnología estará vinculada al vapor.

Pronto la construcción y el tranporte ferroviarios iniciarán un ciclo de expansión que desde Inglaterra se extenderá a otras economías europeas que van entrando en la industrialización ${ }^{14}$.

Paralelamente, el Trabajo va reaccionando mediante su constitución como sujeto, que adquiere diferentes expresiones según las distintas vías y formas de proletarización. El prototipo fabril y minero de la primera revolución industrial está lejos de ser el único exponente de asalarización, dándose ésta también en la agricultura comercial, la industria doméstica, los oficios urbanos, la economía de servicios de la infraestructura urbana o los propios oficios eventualizados, entre otros. Esas distintas expresiones generaban diferentes formas de conciencia y de organización del Trabajo (Eley, 2003: 52-55), pero unas y otras significaron que de las formas más agudas de brutalización laboral y social los seres humanos fueron encontrando la manera de erigir su dignidad como elemento de lucha, en un proceso poco predecible a priori.

Este hecho no puede entenderse sin la formación de una conciencia de distintividad, una conciencia que se autonomiza a partir del compartimiento de circunstancias comunes y de la materialización ideológica de una determinada toma de postura sobre ellas. La conciencia, cada vez más como conciencia de clase, adquiere una dimensión material como forjadora de sujetos colectivos, que a través de su misma unión o colectividad, son más capaces de transformar sus propias circunstancias.

Algunas de las plasmaciones políticas que habían ido generando las primeras expresiones de esa conciencia alternativa, el "socialismo utópico”, el prohudonismo, el anarquismo, el reformismo (cartismo en Inglaterra, o socorros mutuos -Louis Blanc- en Francia), coincidían más o menos en ciertos puntos: la asociación, el mutualismo y la cooperación; la crítica racionalista y humanista a la sociedad burguesa; la reordenación de la sociedad sobre otras bases a través del ejemplo; la huída de la política y, a

\footnotetext{
${ }^{14}$ Mandel (1979: 181-182) nos dice que poco a poco el capital productivo se dedicará cada vez más a la producción de medios de producción en vez de la producción de medios de consumo, si bien ésta sigue siendo predominante pues paradójicamente durante la mayor parte del siglo XIX la composición orgánica del capital fue mayor en este sector II de la industria que en el sector de bienes de equipo. La excepción estuvo en la producción de medios de transporte, pero no cobraría real importancia hasta la segunda mitad del siglo. La máquina de vapor que se colocará sobre ruedas para arrastrar (motor de vapor) los trenes de vagonetas entonces utilizados sobre rieles de madera en las minas de carbón y la fabricación industrial de hierro que permitirá producir rieles resistentes.
} 
menudo, el refugio en pequeños enclaves; la emancipación del trabajo (Eley, 2003). A veces también compartían una política radical de género, porque la "ley civil" que sujeta a unos (trabajadores) al albedrío de otros (patronos) no podría ser trastocada sin romper con la "ley de familia" (supeditación de todos los miembros al pater de familia, al patrón), desafiando de esa manera la trasplantación de la ley de familia a la ley civil (Doménech, 2004).

La intervención de Marx y Engels daría al Trabajo un último impulso para su conversión en sujeto con proyecto histórico o civilizacional propio, mediante algunas precisiones concluyentes:

- La clase obrera tenía que estar organizada políticamente.

- Coordinada por un Partido como fuerza colectiva capaz de desafiar a la clase capitalista organizada (la premisa es que cada parte -cada clase- de la sociedad requiere de un partido propio).

- Para sustituir al Estado (dado que éste se concibe como elemento de dictadura de la clase capitalista y, en general, de una clase contra otra) se necesita una autoridad estatal de transición, que asegure una "dictadura del proletariado" [sinónimo de gobierno general democrático de la clase obrera, esto es, de la absoluta mayoría de la sociedad, mediante la transferencia de todos los cargos estatales a la población (elección directa)], la abolición de la separación de poderes (y con ella el fin de los profesionales de la política), amén de la difusión general de las funciones de liderazgo. Este primer paso constituiría la transformación del Estado de órgano supraordinado de la sociedad en elemento fiduciario de la misma.

Su legado a una clase obrera que adquiría cada vez más conciencia de sí misma fue la importancia del factor económico en la historia; la decisiva influencia de las fuerzas materiales en los logros humanos; la vinculación de las oportunidades políticas a los procesos económicos (Eley, 2003).

Se sentaron así las premisas para el nacimiento del socialismo político:

- Análisis económico del capitalismo

- Programa político para la reorganización general de la sociedad

- La meta de la propiedad colectiva de los medios de vida, así como la producción cooperativa

- Lo social como contrapuesto a la antisociedad capitalista. Esto es, pasar del "individuo soberano" proclamado por la doctrina liberal-capitalista, a la soberanía popular

- Extender los preceptos democráticos al conjunto de la sociedad

- Reorganización de la economía en virtud de nuevos criterios:

-Cooperación

-Propiedad pública

-Socialización de la producción

-Democracia industrial

-Dirección planificada

Las implicaciones de todo ello son sobrecogedoras: por primera vez 
en su transcurso por el planeta los seres humanos osan acometer la tarea de dotarse consciente, planificadamente, de un sistema socioeconómico (ninguno de los que han existido hasta ahora han sido producto de la intencionalidad teleológica humana). Un sistema, además, en el que no tendría cabida la explotación del ser humano por el ser humano.

La formación de una conciencia distintiva advenida paulatinamente en identidad de clase, la organización y combatividad de cada vez más sectores del Trabajo, y sus balbuceos en torno a una construcción de sociedad alternativa, se verían reforzadas por ciertos factores objetivos. Poco a poco, y a pesar de las diferencias en el proceso de proletarización o asalarización, en el núcleo duro de las sociedades centrales la población asalariada se va haciendo mayor que la población activa que continua con nexos no capitalistas. En 1848 el 80\% de la población activa inglesa estaba ya asalariada. En Francia y en Holanda llegaba al 55\%. Eso quiere decir que se iba limitando la capacidad de reemplazo de la fuerza de trabajo. Con ello se incrementa la vida media activa del trabajador como asalariado y también la estabilidad laboral: se dan las primeras regulaciones del trabajo (Dierckxsens, 2003).

Sin embargo, la doble crisis de la segunda mitad de los años 40 (agraria e industrial) llevaría a situaciones límites a la población trabajadora europea. Por un lado, los años 30 del siglo XIX ven cómo las empresas más grandes van haciéndose con la nueva tecnología (el vapor), lo que hace que dejen fuera de la competencia real a los pequeños capitales, los no mecanizados. Al mismo tiempo, tal generalización del vapor a otras empresas hace perder las ventajas competitivas a las empresas que primero le habían introducido, con lo que se da un descenso generalizado de la tasa de ganancia entre 1835 y 1848, que tiene su corolario en la crisis de los valores bursátiles del ferrocarril. Momento álgido de la primera gran recesión capitalista, que combina, por última vez juntas, crisis se sobreacumulación o sobreproducción (crisis capitalista), y crisis agraria de escasez (crisis precapitalista $)^{15}$.

La oleada insurgente del Trabajo no se haría esperar, y tiene su eclosión en 1848 (afectando a Francia, Italia, casi toda la Europa Central y los territorios eslavos hasta la frontera rusa). Ola de agitaciones en la que se suman viejas aspiraciones de la burguesía liberal con reivindicaciones na-

\footnotetext{
${ }^{15}$ La crisis agrícola de 1846-1847, típica crisis de subproducción agravada por la pérdida de la cosecha de patatas con las implicaciones de hambrunas (rematada por epidemia de tifus) y subidas de precios que sembraron las bases del descontento; vino provocada por el desacompasamiento entre el aumento de la población y la estructura agraria, y socavó las bases de la casi autarquía agraria en que vivían las distintas regiones europeas. También puso fin a los restos de la servidumbre feudal que quedaban en la Europa oriental (con la última excepción de Rusia hasta 1861) en donde un sistema de indemnizaciones permitió a los campesinos comprar su propia libertad. En cuanto a las crisis de sobreacumulación, el capitalismo es el único modo de producción en el que la creación de riqueza constituye un problema crítico.
} 
cionalistas y otras propias del incipiente proletariado organizado (la principal expresión del Trabajo organizado para entonces es como proletario). En ellas participan sectores más amplios de población que en ciclos anteriores (1820 o 1830, en los que el proletariado todavía no organizado como tal había hecho las veces de fuerza de choque para unos u otros sectores de la burguesía en pugna).

Las derrotas insurreccionales (con la parcial excepción de Francia) y la amplia represión desatada contra el Trabajo en los años siguientes, asentó el terreno para una reestructuración del poder de clase y una recuperación del proceso de acumulación capitalista, a través de un nuevo modelo.

2. Ese segundo modelo de acumulación capitalista se basó en un fuerte avance tecnológico que repercutió en las ramas industriales ya consolidadas, pero también en la química, la maquinaria, la generación de electricidad, industrias ligeras, desarrollo de las comunicaciones, transportes, etc. El sistema capitalista entra en su fase monopolista, cada vez más incardinado en el Estado, en el que todavía prevalece su expresión autoritaria. No obstante, va cobrando cuerpo el conservadurismo moderno, como intento de interlocución e integración parcial del Trabajo, a través de ciertas protecciones y reconocimiento de derechos.

El inicio de esta nueva expansión vendría de la mano del ensanchamiento cuantitativo y cualitativo del mercado capitalista. El primero gracias a su apertura hacia la Europa central y oriental, a Asia occidental y al océano Pacífico (según Mandel, 1986, la mayor expansión geográfica que haya conocido el capitalismo en su historia), motivando una industrialización extensiva y una nueva revolución tecnológica: el paso de la máquina de vapor al motor de vapor, de la manufactura a la producción industrial de capital fijo; lo cual a su vez genera un fuerte incremento de la productividad del trabajo (o lo que es lo mismo, del plusvalor relativo o tasa de plusvalor).

El lado cualitativo del aumento del mercado capitalista se realiza a través de las revoluciones del transporte, las telecomunicaciones (ferrocarriles, barco de vapor, telégrafo) ${ }^{16}$ el crédito y el comercio (aparición de las sociedades anónimas, los grandes almacenes...), que contribuyen sobremanera a elevar la tasa de circulación del capital (Mandel, 1986: 19). Esta expansión cualitativa se complementó con el descubrimiento de los ricos

\footnotetext{
${ }^{16}$ Con el barco de vapor se acelera la integración de los mercados entre los centros y las periferias capitalistas. El ferrocarril por su parte incrementaría la integración de los mercados centrales (se cierra la brecha tecnológica entre las principales economías europeas). La carrera puntera de las grandes empresas pasará en lo sucesivo por la producción privada de ferrocarriles financiada con fondos públicos.
} 
yacimientos de oro de California ("la fiebre del oro" en el Oeste norteamericano) y en menor medida, de Australia.

Al mismo tiempo, con la importación de granos de las colonias a precios significativamente más baratos que los producidos en los países europeos industrializados, el valor de la fuerza de trabajo en estos últimos disminuye, haciendo caer los salarios reales (esto de paso arruina también al campesinado y al rentismo rural improductivo) ${ }^{17}$.

Mientras tanto, se generaliza la fábrica, en la que Marx llama la "fase orgiástica del capital” (la acumulación se realiza combinando la plusvalía absoluta y la relativa). La acumulación en maquinaria sustituye mano de obra, al tiempo que el sector primario continúa proporcionando mano de obra barata descualificada, afianzando un desarrollo desigual entre sectores.

Este ciclo encuentra su decadencia con la creciente resistencia obrera a la sobreexplotación (García-Durán, 2002), el aumento en cualidad organizativa del Trabajo y la reducción de su sustituibilidad al quedar menos ejército de reserva que asalarizar ${ }^{18}$. El Trabajo constituido como clase obrera (y dentro de ella su sujeto es el MO) ha incrementado notablemente la acción reivindicativa. A partir de la segunda mitad del siglo XIX el carácter antagonista de la relación Capital/Trabajo expresado a través de la acentuación de la tasa de explotación, acarreará una ofensiva sin precedentes del Trabajo en forma de huelgas y la creación de organizaciones. El MO va conquistando los derechos políticos, el derecho a la huelga, a constituir sindicatos, y arañando unos derechos sociales hasta entonces apropiados por la burguesía en exclusividad.

Se consolida con ello la nueva realidad de la ciudadanía (siempre vinculada a la distinta correlación histórica de fuerzas en la lucha de clase), que va de la mano de la construcción de un nuevo ámbito: lo social, entendido como espacio de interacción, negociación y administración, como campo en el que llevar a cabo la acción e intervención de los diferentes agentes sociales ${ }^{19}$.

\footnotetext{
${ }^{17}$ Con la penetración capitalista en las colonias comienza a afianzarse la división internacional del trabajo, que tiene a la sazón su expresión en la producción capitalista de materias primas baratas. Con ello, la esclavitud resulta obsoleta por poco rentable (Mandel, 1979).

${ }^{18}$ En las sociedades en las que se ha desarrollado más rápidamente el capitalismo buena parte de la población campesina se ha convertido ya en proletaria. Todas estas razones motivan que se tomen las primeras medidas generales de salud pública, los primeros seguros frente a accidentes laborales. Lo que quiere decir que desciende lenta pero constantemente la mortalidad, va aumentando la esperanza de vida de la población trabajadora (empieza la transición demográfica).

${ }^{19}$ Estos procesos transforman la propia concepción de sociedad civil, ahora vista a la vez como sujeto interviniente y como lugar de confluencia de las luchas, pactos o interacciones sociales en general En adelante al menos dos concepciones de la sociedad civil se confrontarán: la burguesa (verticalizada y heterónoma) y la popular (no dada, sino como fruto cambiante de la autoorganización, autónoma).
} 
Nace la I Internacional (1864). Se da cierto grado de parlamentarización de la relación Capital/Trabajo (por primera vez surgen partidos obreros con una organización a escala estatal y centrados en la pugna parlamentaria, fruto de las liberalizaciones políticas conseguidas entre 1867$1871^{20}$, llevando a cabo la agitación legal a una escala superior a la local, donde se ve la influencia también de la I Internacional), que sin embargo es contrarrestado por la todavía generalizada violencia descarnada del Capital. La irreductibilidad del Trabajo tiene su corolario en la Comuna de París (1871). Hará mostrar al Capital su lado más sanguinario.

Entre los factores 'objetivos' de la decadencia del segundo ciclo de acumulación capitalista se da el agotamiento de la explotación agrícola (ya capitalizada) y de las innovaciones técnicas existentes (que al generalizarse hace descender la tasa media de ganancia, esta vez en una dimensión considerablemente mayor dada la internacionalización de la economía). La exacerbada competencia de las empresas comerciales a escala de la naciente economía-mundo terminó de generar la caída de la tasa media de ganancia. Esto significó una nueva depresión, en la que descienden los precios y los tipos de interés (Arrighi, 1999: 197), cae el crecimiento económico y baja el comercio internacional. Tiene lugar una nueva destrucción de capitales no competitivos. Las empresas grandes se expandirán a costa de las otras (gracias a sus ventajas competitivas en las economías de escala).

Esto trae como consecuencia la primera "huída" colectiva del sistema internacional paneuropeo hacia las finanzas. El "capital excedente" (no reinvertible dada su escasa rentabilidad) se acumula al margen de los canales habituales de inversión en mercancías, sentando las bases de una expansión financiera hacia el exterior, que se combinó con la creciente atracción de capitales externos que ejercían los centros financieros europeos y muy especialmente la City londinense (Arrighi, 1999: 196-197). Es la primera fase de financiarización universal.

A partir de 1875 la mayor parte de la población activa está ya asalariada en las economías de capitalismo más desarrollado, lo que quiere decir que se pierde aún más la capacidad de sustituirla, y con ello se facilita el incremento de los salarios reales ${ }^{21}$. Esto se correlaciona con que la fuerza de trabajo adquiera mayor poder social de negociación y por ende más posibilidades de hacer valer sus reivindicaciones político-laborales. Lo que también explica su paulatina integración.

\footnotetext{
${ }^{20}$ Sin embargo, según se va consiguiendo la incorporación obrera a las instituciones representativas de la nueva sociedad, se va despojando a éstas de atribuciones o poder real.

${ }^{21}$ Las grandes emigraciones internacionales de la fuerza de trabajo (el excedente de trabajadores de la revolución industrial) de las sociedades centrales europeas contribuyeron en gran manera a la disminución del ejército de reserva de éstas. Como advirtiera Mandel (1986: 23), aquellos flujos migratorios (finales del XIX y principios del XX) fueron de mayores dimensiones en relación con la población mundial que los que se producirían al final del siglo XX.
} 
El poder que adquirían los sujetos de clase como Movimiento frente al Capital va modificando sustancialmente a éste (se dirá que le hace entrar en un proceso de negociación). Se gesta así el "conservadurismo moderno", que propugna concesiones socioeconómicas y políticas al Trabajo, a cambio de que éste se convierta en un interlocutor racional (que acepte el sistema y actúe dentro de su lógica).

Las negociaciones pasan a ocupar más espacio en detrimento de las acciones de choque. Nace la II Internacional (1889). Pero la vertiente anarquista del MO se ha hecho a un lado: predica a la sazón la transformación por el ejemplo (efectismo de los golpes) y la pugna por el control en el lugar de trabajo y por la apropiación colectivizada de los medios de producción. Pero deja una seria duda de si su desprecio por la política con minúsculas (como campo de pugnas intercapitalistas) no incluye también, de alguna manera, el de la Política con mayúsculas (como confluencia y lucha sobre el propio devenir social).

Concomitantemente, el desarrollo de las fuerzas productivas provoca la necesidad de incrementar la formación de la fuerza de trabajo. Aumenta la diferenciación cualitativa entre ella (y en consecuencia, el distanciamiento subjetivo en su interior, la disparidad de conciencia política e identitaria). Como quiera que también aumenta el costo invertido en la fuerza de trabajo (y disminuye substancialmente su sustituibilidad), se eleva igualmente su aseguramiento (seguros de enfermedad, incapacidad, vejez, muerte..., en principio sólo para su sector cualificado Dierckxsens, 2003-).

El Trabajo ha entrado en su versión socialdemócrata clásica. Donde más avanzada está su institucionalización genera todo un entramado social paralelo (hasta el punto de llegar a postular la separación entre "dos mundos": el del Trabajo al margen del que hegemoniza el Capital -Domènech, 2004-), confiando en la caída del capitalismo por su propio peso ${ }^{22}$. El sector más antisistémico del Trabajo se desplaza a los países semiperiféricos de Europa (sur y este del continente) y de América (aquellos que han alcanzado mayor grado de industrialización, especialmente en el Cono Sur. Aquí al acabar el siglo XIX la fuerza de trabajo asalarizada rondaba ya el $50 \%$ del total; en los años 20 del siglo XX representaría dos tercios del total de la población activa).

\footnotetext{
${ }^{22}$ Para no quedarse aún más extraña a las masas obreras que le habían dado la espalda, la Iglesia Católica intenta contrarrestar su pérdida de influencia en ellas a través de los sindicatos y partidos cristianos. Abogaba por un entendimiento entre patronos y obreros amparado en la "justicia" y la "fraternidad" humana, pero eso sí, preservando como intocable el "derecho natural a la propiedad privada”, “derecho" que corría necesariamente paralelo a la prédica de la "resignación” para las grandes mayorías que se veían privadas del mismo. Todo lo cual no fue óbice para que con el tiempo se desarrollara también una vertiente política del cristianismo de izquierda (que más tarde tendría su réplica en otras religiones, aunque palmariamente contrarrestada por el papel mayoritariamente conservador que asumiría en las periferias las formas de conciencia religiosa subordinadas -ver p.e. nota 42).
} 
En las semiperiferias europeas se produce una mucho más lenta implantación de las relaciones sociales de producción (RSP) capitalistas, acompañada de una más tardía también constitución del Trabajo en sujeto (todavía es la expresión campesina del Trabajo la que protagoniza su lucha de clase, sin formada conciencia de clase). Los sujetos del Capital representados por los sectores burgueses liberales, tienen que coaligarse por más tiempo con las expresiones reivindicativas del Trabajo, contra el Viejo Orden precapitalista.

En la América llamada "Latina” la expresión colonial de las RSP capitalistas ha acelerado el proceso de transformación de la base económica, pero se ancla por el contrario, debido a su propio carácter dependiente, en relaciones políticas del Antiguo Régimen. Estas contradicciones tendrán su eclosión en forma de lucha interburguesa. Esto es, entre la burguesía periférica (liberal, autodenominada "patriota” o nacionalista, propugnadora de la forma social de organización estatal también para las tradicionales formaciones coloniales), y la burguesía semiperiférica (ibérica), mayoritariamente anclada en formas de dominación precapitalistas, propias de la expansión del capital mercantil; defensora todavía, por tanto, de formas coloniales de acumulación.

La burguesía criolla contará para su proyecto liberal-capitalista con el prolongado apoyo de expresiones campesinas y de nacientes organizaciones del Trabajo asalariado. Mientras que el Trabajo en su expresión étnico-cultural (extraexplotado y oprimido en su condición de "indígena”), ha dado por el momento sus últimas luchas en pos de constituirse en un sujeto "emancipado", no capitalista; pero en cambio se manifestarán recurrentemente luchas concretas contra la sobreexplotación y el abuso de trato o el sometimiento vergonzante, así como por la posesión de la tierra. Se expresarán a veces a través de milenarismos no sólo indígenas sino también campesinos.

El resto del mundo, con muy contadas excepciones, va siendo incorporado a través de la colonización al sistema estatal paneuropeo (que cuenta ya con su extrapolación norteamericana independiente).

En las sociedades centrales el Capital responderá al fortalecimiento del Trabajo agilizando su capacidad para organizarse como clase, coordinándose a través de sus propias organizaciones, con las que en adelante desafiaría y combatiría al Trabajo organizado con todo tipo de medidas. Pero además, responderá también con su proceso de monopolización. Si bien éste es un proceso forzado por su propia dinámica interna [dado el paso del sector II de la industria (bienes de consumo) -que requiere relativamente poco capital- al sector I industrial (bienes de producción) -donde la concentración de capital requerida es mayor- (Mandel 1979: 181), lo es también porque con el agotamiento de la fase expansiva de 1850-1873, el modo de regulación competitivo ya no era propio para enfrentar un Trabajo cada vez más organizado y cohesionado en sus reivindicaciones, que entre otras cosas impedía la drástica reducción en el índice del salario real 
para favorecer el restablecimiento de la tasa de explotación, la cual no contrarrestaba ya la caída de precios. O dicho de otra forma, la tasa de salario se había vuelto muy poco flexible a la baja, impidiendo la regulación de la tasa de ganancia por medio de la tasa de salario.

Es así, por tanto, que el Capital emprende un movimiento orientado a restringir la competencia a través de la obtención de reglas que permiten establecer protecciones y privilegios mediante acuerdos entre capitalistas sobre precios o volúmenes de producción, y mediante la concentración industrial en sentido estricto. Eso quiere decir que la lucha de clases tiene mucho que ver con el fin del capitalismo competitivo y la formación del capitalismo monopolista, y no sólo las economías de escala (ver p.e., Dockes y Rosier, 1983). A ello contribuyó que la crisis dejara fuera de la competencia a las empresas menos preparadas para el salto.

Amén de esto, el Capital buscaría nuevas líneas de producción (desplazamiento productivo) en las que obtener mejores ganancias [según Silver (2005), aquél se desplaza de la industria caracterizadora del siglo XIX, la textil, a la automovilística, que sería la prototípica del siglo XX] $]^{23}$. Así pues, el nuevo ciclo de expansión que se inicia a través de las industrias química y eléctrica, y que se extiende hacia las sociedades periféricas, se hará monopolísticamente.

3. Este tercer modelo de acumulación capitalista se extiende desde finales del siglo XIX hasta la Segunda Guerra Mundial, y combina los modos extensivo e intensivo de crecimiento. Con él se generalizan los motores de combustión interna y eléctricos, surgen nuevas ramas industriales y la utilización del petróleo como recurso energético. Se «racionaliza» el trabajo de cara a un mayor rendimiento de la mano de obra (taylorismo) a la par que se desarrolla la producción en cadena (fordismo). Se completa el dominio imperialista del mundo. Pero a mitad del ciclo la crisis capitalista genera una nueva ola insurgente del Trabajo, a la que el Capital responderá a través de la militarización como principal expresión regulativa. El capitalismo monopolista de Estado asumirá sus expresiones más violentas y terroristas contra el Trabajo: el pistolerismo, el fascismo y la guerra.

\footnotetext{
${ }^{23}$ La tesis de esta autora es que una línea de producción tiene su fase de innovación o lanzamiento, que reporta auge de ganancias y desestructuración obrera, hasta que primero la fuerza de trabajo se recompone y/o reorganiza frente a esta nueva línea (a menudo acompañada de nuevos procesos tecnológico-organizativos), haciendo disminuir la tasa de plusvalía en su fase de madurez, hasta que posteriormente la propia competencia capitalista hace descender la tasa de ganancia, al estandarizarse esta nueva líneas entre las empresas. La resistencia del Trabajo y la competencia intercapitalista motivan que a partir de la fase de madurez y sobre todo en la de estandarización, se busque la salida del desplazamiento espacial, hacia otros lugares donde no se haya desarrollado esta línea de producción con posibilidades de que allí se rentabilice. Proceso que al irse agotando dará paso a la opción de sustitución por una nueva línea de producción.
} 
La explotación y expansión coloniales se incrementan mediante la exportación de capitales, una vez que, gracias a la previa inversión en los transportes, ya sí se estaba en condiciones de implantar la base industrial (de bienes de equipo -la producción de máquinas-) en los países periféricos. Implantación que absorbería los recursos locales disponibles para la propia acumulación de capital, implicando la apropiación del plusproducto social local por parte del capital extranjero. Por otro lado, los recursos que quedaban disponibles en las periferias capitalistas se fueron concentrando en los sectores de exportación de materias primas, en los agenciales para las empresas capitalistas extranjeras como la especulación con las tierras, la erección de bienes raíces, la usura, las empresas de servicios de las pequeñas y las lumpenburguesías locales (casinos, cierto turismo rentable, negocios más o menos gansteriles, etc.) (Mandel, 1979). Es decir todo eso que Gunder Frank llamó “desarrollo del subdesarrollo”. Con lo que se acentuaba el desarrollo desigual entre países.

Por su parte, los monopolios tienen en el Estado su principal agente económico. Los monopolios estatales de las principales potencias capitalistas se lanzan a la conquista de una nueva expansión mundial, entrando así en la fase de imperialismo puro.

“Lo que cambió entre el capitalismo de libre comercio y el imperialismo clásico fue la articulación específica de las relaciones de producción e intercambio entre los países metropolitanos y las naciones subdesarrolladas. El dominio del capital extranjero sobre la acumulación local de capital (...) sujetó en esta etapa el desarrollo económico local a los intereses de la burguesía de los países metropolitanos” (Mandel, 1979: 56-57)

África, Asia Occidental y Oriental (incluida China) quedan incorporadas a grandes bloques imperiales coloniales o como esferas de influencia semicoloniales. Hay un crecimiento cualitativo de la exportación de capital a los países periféricos o de capitalismo dependiente, al tiempo que las técnicas capitalistas de producción consiguen una bajada de los precios relativos de las materias primas. Con ello se ralentiza la velocidad de crecimiento de la composición orgánica del capital. A esto se le suma el logro del incremento de la tasa de plusvalor gracias a una nueva revolución tecnológica, la de la electricidad, y a la aplicación científica en los procesos de producción con vistas a incrementar la productividad y reducir los tiempos muertos (tylorismo o sustracción del tiempo obrero), todo lo cual está en la base de la recuperación de la tasa media de ganancia, que lanzará una nueva onda expansiva del capitalismo (a partir de comienzos de los años 90 del siglo XIX -hasta la debacle bélica de los años 10 del siglo XX). Se da una reorganización de la empresa capitalista a través de la "revolución organizacional” o managerial y la descomposición de la propiedad en sociedades anónimas.

Este ciclo va unido al paulatino predominio de la plusvalía relativa sobre la absoluta en las sociedades centrales. En consecuencia se facilitan las condiciones para la integración de la clase obrera (cada vez más de sus sectores organizados son convertidos poco a poco en "actores racionales", corresponsables del orden social). 
La Segunda Internacional fue adaptándose a las transformaciones objetivas que se habían producido en el capitalismo de finales de siglo (generalización del sufragio, reconocimiento de la libertad de asociación, desarrollo de los sistemas parlamentarios), con el consiguiente desplazamiento del conflicto frontal, de base, a la arena política institucional, y la primacía de la negociación y concertación. Paulatinamente se impone la apuesta por las reformas progresivas y la solución de los problemas cotidianos, inmediatos, de la clase trabajadora.

Sin embargo, este ciclo expansivo resultará ser sumamente inestable según se acrecienta la dimensión mundial y mundializadora del Capital. La pugna por la repartición del mundo entre los grandes monopolios estatales convoca un acelerado incremento del armamentismo, esto es, de los gastos improductivos [desciende el capital fijo y los medios de consumo, provocando una dispar ralentización económica en ciertas economías centrales, que experimentan, no obstante, un breve ascenso económico entre 1924-1929]. La competencia interimperialista genera una inestabilidad de unos 30 años [1914 a 1945] por la primacía en el (nuevo) sistema paneuropeo internacional y el consecuente dominio de la centralización del capital.

La caída de las ganancias de la “nueva economía” de la época, la de bienes de consumo duraderos, subyace al crac bursátil de 1929, cuyas consecuencias se arrastrarían durante toda la década de los 30.

“El alza significativa de la composición orgánica del capital como resultado de la electrificación generalizada produjo una tendencia descendente de la tasa de ganancia que sólo hubiera podido ser neutralizada por un correspondiente aumento significativo de la tasa de plusvalía” (Mandel 1979:185). Esto último, sin embargo, fue impedido por la recuperación combativa del Trabajo tras la revolución soviética. Después de ésta se produce una recomposición revolucionaria de las vanguardias del MO, que tiene una de sus más destacadas expresiones en la Tercera Internacional y la fundación de los Partidos Comunistas; lo que unido a la crisis de acumulación capitalista genera un amplio deterioro de las condiciones de integración de la fuerza de trabajo y con ello un estado de inestabilidad o insurgencia de la misma (soviets de Hungría, Berlín, la Viena Roja, las comunas ucranianas...).

El Capital se ve cada vez más urgido a enfrentar la creciente fuerza y combatividad del Trabajo. De esta manera, el pistolerismo y todo tipo de medios violentos antihuelguísticos y antiobreros, dan paso al fascismo aprovechando la enorme capacidad de atracción y difusión de los dos movimientos sociales más masivos y fuertes del siglo XIX: el socialismo y el nacionalismo ${ }^{24}$. En adelante el fascismo se constituiría en el principal arie-

\footnotetext{
${ }^{24}$ El Capital no inventa nada en este salto histórico a su versión fascista, tan sólo amalgama los presupuestos de uno y otro movimiento, forzándolos o deformándolos monstruosamente: un mensaje de apariencia "socialista" dirigido no a la clase mayoritaria sino a la "nación" (como comunidad); un nacionalismo a la medida no sólo de la burguesía (que hasta enton-
} 
te de agresión social del Capital contra el Trabajo. Su sombra o amenaza, junto con la de la guerra, sirvió también en todas las sociedades centrales para la represión interna del MO.

En las periferias “independientes” (América "Latina”) se aprovecha la coyuntura de elevación de demanda de materias primas para reestructurar las bases del Estado a través de dinámicas más marcadamente clientelares y realizar una ofensiva integradora de las poblaciones (exceptuando a los sectores indígenas). La revolución mexicana sería la piedra de toque que marcaría el cambio de dinámica.

En las sociedades centrales, la grave fractura habida en el Trabajo, entre la II y la III Internacional; la sujeción igualmente internacional del Trabajo a las cambiantes, poco explicadas y menos debatidas directrices de la Komitern ${ }^{25}$; el propio repliegue "en su mundo" de la socialdemocracia europea y su distanciamiento de los sectores medios y autónomos del Trabajo (propiciando que ante los cortocircuitos en la acumulación capitalista buena parte de ellos se dejara atraer por la vertiente fascista del Capital), contribuyeron a la victoria de la contrarrevolución.

La enorme "destrucción creativa” que se había realizado, y las derrotas de las expresiones más insurgentes del Trabajo primero en las sociedades centrales a través de las dictaduras nazi-fascistas o de su amenaza, así como mediante la propia guerra (o la economía de guerra), y después en las semiperiféricas (derrota de las insurrecciones húngara, ucraniana y griega, masacre colectiva de la República española y, en general, la destrucción en todos lados del frentismo -que tiene su epítome en la sumisión del Frente Popular francés-); la ofensiva general en los países de la Europa occidental

ces había sido patrimonio suyo) sino pretendidamente de todas las clases (Núñez, 1993). Oxímorons acordes con el desprecio fascista por la razón y la ciencia, mientras que sus viscerales antimarxismo, antiliberalismo y anticonservadurismo corren parejos a su negación de la justicia asociada a la igualdad, su desprecio de la libertad, la democracia y la propia posibilidad del progreso humano.

${ }^{25}$ Los bandazos que siempre dio la Komintern, antes incluso de su periodo estalinista, sobre las claves de alianzas a seguir, nos han dejado huérfanos de una buena guía estratégica. De las 21 condiciones comunistas irrenunciables del $2^{\circ}$ Congreso, que excluían a los partidos de la Segunda Internacional, se pasó en 1922 al Frente Unido con otras fuerzas de izquierda. Dos años más tarde la Komintern aprobaba una nueva “bolchevización” de las organizaciones. En 1935 terminó propugnado el Frente Popular, con lo que cambió también el vocabulario: la "lucha de clases” dejó paso a la vaga acepción de "pueblo", para terminar aceptándose incluso la de "nación". No es de extrañar, por eso, que un poco después (en 1943, con la disolución de la Komintern) se propugnara el Frente Nacional, teniendo a la "democracia" como único referente (todas las fuerzas "democráticas” contra el fascismo). De ahí se rescataría más tarde el concepto de sociedad civil (siempre intentando las fuerzas liberales y neosocialdemócratas que estuviera lo más alejado posible de la formulación que de ella hicieran Marx y Gramsci). 
que supuso la Guerra Fría y el Plan Marshal $^{26}$ (con su correlato del McCarthysmo en Estados Unidos, válido para todo el continente americano como martillo contrarrevolucionario -véase el estancamiento institucional de la revolución mexicana), dejó las manos libres al Capital para el inicio de una nueva onda expansiva, que se apoyaba en el disciplinamiento del Trabajo y el consiguiente aumento de la tasa de plusvalía (entre el 100 y el 300\% en algunos de los casos principales -Alemania, Japón, Italia, Francia, España-).

A esto se sumaría la desaceleración de la tasa de crecimiento de la composición orgánica del capital con la caída de los precios relativos de las materias primas (tras el acceso casi monopolístico de EEUU al petróleo barato de Asia occidental) y el abaratamiento de buena parte de los elementos de capital fijo en la década de los 50, junto al aumento vertiginoso de la velocidad de circulación del capital (telecomunicaciones, crédito, mercado monetario internacional, nacimiento de las transnacionales). Todo lo cual da como resultado el brusco aumento de las tasas de ganancia y de acumulación de capital, potenciadas por la posibilidad de invertir el excedente en el sector armamentístico que se constituía en el auténtico motor de la economía USA, cuyo Estado se basaba en él para generar el ciclo de demanda que el Estado keynesiano realizaba en Europa.

4. El cuarto modelo, que llegó, con sus estertores, hasta el comienzo de la penúltima década del siglo XX, fundamentó el modo intensivo de crecimiento, posible gracias a la «revolución tecnológica» que conlleva a su vez la mercantilización de la actividad científica y su incorporación al proceso productivo. Se generaliza el montaje en cadena y con él la asignación de un puesto fijo a cada trabajador, desarrollando al máximo la especialización y el

${ }^{26}$ Además de sus consecuencias económicas, el Plan Marshall actuó de gigantesco remodelador de la política y de la relación de fuerzas Capital-Trabajo europeas, imponiendo allá donde se aplicó una concepción y práctica de la democracia según el modelo liberal estadounidense, erradicando opciones políticas que apuntaban a una transformación substancial de las sociedades capitalistas (con la prohibición, por ejemplo, de partidos comunistas que habían protagonizado la resistencia antifascista y encabezaban en buena medida la transición postbélica en unos u otros países). Se aceptaba, en compensación, la regulación keynesiana para garantizar la paz social en Europa, y mediante la propuesta de unión transfronteriza de las economías de ésta (desde el Plan Schuman a los Tratados de Roma), procurar la libre circulación de las mercancías estadounidenses en la parte occidental del continente, para mayor crecimiento económico de Estados Unidos. En adelante, al dividirse Europa en dos, la defensa de "Occidente" o del "mundo libre" iría sustituyendo los esfuerzos o anhelos de transformación o superación del capitalismo, que se consolidaba como incuestionado, confinando a la socialdemocracia dentro de los límites del propio keynesianismo [en 1959, el Congreso de Bad Godesberg, del SPD alemán marca la ruptura con la vieja socialdemocracia, en cuanto que a partir de entonces ya no se contempla al sistema capitalista como un orden a superar. Este Congreso serviría de referencia a la práctica totalidad de las corrientes dominantes del resto de la socialdemocracia europea y mundial (Eley, 2003)]. 


\begin{abstract}
aprovechamiento de los tiempos (tylorismo-fordismo). En su seno se han completado también los procesos de monopolización de los mercados y de intervención del Estado en la regulación de la dinámica económico-social, así como el auge del sector financiero. Mientras tanto, el neocolonialismo sustituyó a la explotación directa de los recursos planetarios por parte de las economías centrales, mediante su dominio mundial en todos los ámbitos asentado en una acabada división internacional del trabajo. La conquista de derechos socioeconómicos y los elementos regulatorios keynesianos que propiciaron un Estado Social, junto al círculo virtuoso de producción-consumo y la elevación de los salarios reales en las sociedades centrales, se concitan para la integración del movimiento obrero y una generalizada complicidad del Trabajo.
\end{abstract}

Los capitales que durante la Gran Depresión no se habían podido invertir, ni se habían exportado a las colonias (“capitales excedentes”), se volcaron en la nueva fase de acumulación hacia la nueva reconstitución del sector II industrial, para la fabricación de bienes de consumo duradero (aplicación de la revolución tecnológica especialmente a la producción de automóviles y de aparatos eléctricos para el hogar -electrodomésticos-). Esto hizo aumentar la composición orgánica del capital en el sector I, afectando su tasa de ganancia. En él se concentró la ofensiva para realizar la recuperación de ésta, que Mandel (1979: 186) concretó en los siguientes puntos:

- Valoración inmediata de los capitales excedentes por medio del rearme (“Guerra Fría”).

- Renovada penetración masiva del capital en la producción de materias primas, pero esta vez con tecnología industrial avanzada, para reducir el costo del capital constante.

- Reducción del capital variable en la producción de mercancías, a través de la automatización o la semiautomatización.

Conseguida la elevación de la tasa de ganancia, la expansión de capital se disparó mediante la afluencia y uso de capital "excedente" acumulado pero no valorizado durante la depresión, provocando una nueva onda larga de acumulación, bajo la hegemonía de EE.UU. que impuso contención a la rivalidad intercapitalista a escala planetaria. Por el contrario, el mercado capitalista se había achicado, gracias a la “desconexión” del mismo que realiza la URSS y los países de Europa oriental que quedaron bajo su hégida, además de China y otros países de Asia oriental.

Se inaugura así en las sociedades centrales la fase de capitalismo keynesiano que conlleva la siguiente secuenciación: integración del MO"Pacto keynesiano" / Exacerbación de la diversificación del Trabajo y consiguiente multiplicación de sus formas de conciencia ${ }^{27}$ / Reformismo -Cor-

\footnotetext{
${ }^{27}$ El modo de regulación estatal-keynesiano potenciará en las sociedades centrales un acrecentamiento de la diferenciación de la clase trabajadora, con la acentuación de la división
} 
porativismo colectivo / Conquista de derechos socioeconómicos para el Trabajo / "Institucionalización del conflicto” / Depredación de la naturaleza / Incorporación de un nuevo ejército de reserva a través de las grandes migraciones periféricas hacia las sociedades centrales / Era del desarrollo basada en la fe en el desarrollo indefinido del capitalismo y en el desarrollo gracias al capitalismo ${ }^{28}$.

Esto es congruente con la aplicación sistemática de la ciencia a la producción, en una permanente búsqueda de aceleración de la innovación tecnológica, que provoca a su vez la aceleración de la obsolescencia de la maquinaria y su correlato en la aceleración de reemplazo del capital fijo en uso. La organización sistemática de la investigación y el desarrollo como un negocio específico implica que la innovación se convierte en una rama insoslayable de la empresa capitalista.

El MO es en alta medida encauzado mediante sus organizaciones de representación política y laboral dentro del marco de las relaciones sociales de producción capitalistas, en una forma de regulación corporatista [organización de intereses a escala estatal a partir de grandes organizaciones que representan coaliciones de fuerza, suprasectoriales, de actores cohesionados en torno a incentivos y elementos ideológicos expresos, que tratan de articularse en programas de actuación económica y sociopolítica convergentes (Alonso, 1999)]. Lo que significa que el MO incidirá en la estructura política en gran medida como un grupo de interés organizado, en dinámicas de negociación y de conciliación de intereses contrapuestos. Se sitúa, de esta forma, en el ámbito general del macrocorporatismo, propio de las sociedades centrales europeas de esta fase. Se produce, por tanto, la transición de las expresiones organizativas obreras a formas burocráticas, centralizadas.

La gran mayoría del Trabajo, incluso muchos de sus sectores más politizados, asumirá una vocación gradualista defensiva, basada en el logro táctico de mejores condiciones en los distintos órdenes (laboral, social, ciudadano...), que se aceptan como separados, sin proponerse ya una ofensiva integral, altersistémica ${ }^{29}$. Se recobra además el espejismo de la unidad obrera a partir de su pretendida unicidad, gracias a la apariencia de uniformización que propaga el prototipo del obrero industrial u obreromasa.

Hay, no lo olvidemos, un denominador común en los proyectos políticos de las “vanguardias” del Trabajo: su intento -en la teoría o en la

\footnotetext{
${ }^{28}$ Se "inventa” la cooperación al desarrollo, como forma de apoyar el manteniendo de las estructuras de desigualdad, así como mecanismo de exportación e inversión a medio plazo de capitales excedentes (ver Piqueras, 2008).

${ }^{29}$ Lo cual viene reforzado por el entendimiento tácito entre las elites burocráticas estalinistas y las plutocracias capitalistas sobre el ámbito de la micropolítica, que conduce a que, entre otras muchas consecuencias, los Partidos Comunistas se afirmen en cada vez más lugares en la vía oportunista, o de supeditación estratégica a opciones reformistas intracapitalistas.
} 
práctica- de negación de la propia pluralidad del Trabajo y la desconsideración de las múltiples contradicciones que también le atraviesan, ancladas en la imaginería política del tercer modelo de acumulación, que resultó dominada finalmente por la versión estalinista del "socialismo" (con las desastrosas consecuencias para los sectores revolucionarios del Trabajo, como para la propia proyección estratégica del mismo). La pluralidad realmente existente intentó ser “superada” mediante la centralización organizativa de las expresiones políticas surgidas de su seno, que se prepararon a partir de un cierto momento para concentrar sus esfuerzos en la esfera política con minúsculas (en sentido estrecho o meramente institucional-estatal), es decir, la identificada con el ámbito del poder también con minúsculas. Se descuidaba así el Poder con mayúsculas que era inherente al Capital: su capacidad de regular el metabolismo del cuerpo social en su conjunto, generando 'sus' propios individuos, su propia 'cultura’ interna, sus propios motivos y modos de vida y de disciplinamiento social (Mészáros, 2003).

En cualquier caso, en esta fase del Capitalismo Monopolista de Estado nos las vemos ya con un MO que comparte las estructuras burocráticas propias del corporativismo macrosocial, y de su institucionalización como elemento del Estado ("Social”). Al organizarse para la contienda en esos límites estrechos, las expresiones políticas del Trabajo adoptaron las formas y estructuras del adversario. En contrapartida, posibilitaron un creciente poder social de negociación del Trabajo, que fue limitando progresivamente la tasa de ganancia capitalista al aumentar significativamente la parte del capital variable en la composición orgánica del capital.

La otra gran vertiente de integración del Trabajo en las sociedades centrales vendría dada por el desarrollismo-consumismo propio del capitalismo keynesiano y se tradujo por la complicidad creciente del Trabajo en el ciclo de acumulación del Capital (producción-consumo-producción), en el que todos los aspectos de la Vida quedan subordinados a la mercantilización. La necesidad para el Capital de acelerar los tiempos de realización de la plusvalía a través de la venta hacen del consumo (masivo) una forma de vida, un estimulador del rendimiento laboral, un vehículo de integración cuando no cooptación sociopolítica, y un discriminador de estatus sin igual [con productos diferenciados para cada clase social y para cada segmento de clase. Desideratum de vida, la realización personal queda más y más vinculada al consumo, dándose la subsunción real del consumo al capital o subordinación del Trabajo no sólo en la producción sino también en el consumo [depende para vivir no sólo de vender su fuerza de trabajo al Capital, sino también del entero consumo de su vida (para consumir su vida consumiendo o produciendo para consumir)].

Con ello se consigue la sustracción del ocio obrero (toda la vida supeditada y también dedicada al ciclo de acumulación del capital), extendidos procesos de desclasamiento afirmados por la expansión de la ideología de la “clase media universal” (sustracción de la conciencia de clase). 
Los desafíos a este espejismo keynesiano vendrían dados a través de la irrupción de otros tipos de sujetos del Trabajo, por mor de ciertas contradicciones y fracturas que se fueron haciendo más visibles y/o cobrando existencia política, como la de género ${ }^{30}$ o las étnico-nacionales, las procedentes del modelo desarrollista-militarista, las que suscitaba la depredación de la Naturaleza, etc., asumidas como "inevitables" en el pacto de clase keynesiano. Fracturas que darían origen a los llamados "Nuevos Movimientos Sociales" (NMS), que cobraron vida e incidieron fundamentalmente en la esfera reproductiva o circulatoria, con su repolitización de lo social y su atesoramiento de horizontalidad y de altos niveles de democracia interna como claves organizativas. El enfrentamiento a los múltiples poderes en que se sustenta el Poder, la recuperación del ocio liberado o la liberación del consumo, la emancipación del yo o la reivindicación de los colectivos sin voz, como sus objetivos más inmediatos, les alejaría casi siempre, sin embargo, de la intervención en torno al propio Poder (el central en la sociedad capitalista, el de clase, que pone todos los otros poderes al servicio del Capital). Centrados fundamentalmente en la esfera de la Reproducción o Circulación, los NMS desatendieron igualmente la de la Producción.

El estado de cosas descrito es atravesado por unas u otras semiperiferias y periferias con diferencias notables entre ellas en el tiempo. Debido a la endeblez de sus posibilidades redistributivas y, en general, a su mayor carencia de mecanismos de legitimación, el Capital se ve forzado en ellas a mantener su expresión dictatorial por más tiempo, o incluso a recuperarla cuando las circunstancias lo aconsejan.

América "Latina” experimenta en los primeros años de la segunda postguerra mundial una activación de sus mercados internos, gracias a las necesidades del momento de materias primas por parte de los países centrales. Lo que eleva los precios de las mismas, produce una creciente demanda de mano de obra y el consecuente aumento de los salarios, que en conjunto permite el surgimiento de regímenes populistas o nacionalistas con cierto respaldo de masas.

Procesos que no tardan en invertirse cuando la reordenación económica mundial golpea de nuevo al subcontinente. Entonces el Estado deja de lado su (escasa) atención a la demanda y comienza una nueva escalada represiva. Las burguesías centrales y periféricas estrechan aquí sus lazos

\footnotetext{
${ }^{30}$ Probablemente es la lucha de las mujeres y sus conquistas como Trabajo generizado las que más han marcado la ruptura del siglo XX con respecto a la usurpación de oportunidades de vida al interior del Trabajo. Emancipación de género que intenta abrirse paso muy dificultosamente primero en las sociedades centrales y todavía con más obstáculos en el resto de formaciones sociales del planeta. En general, quizá sólo la versión trotskista del marxismo fue capaz a la sazón de establecer ciertas sinergias con los nuevos rompimientos del Trabajo en forma de NMS. El trotskismo expresaría en adelante una de las opciones más rupturistas en el capitalismo tardío, si bien siempre tensionada internamente por su perenne situación de minoridad.
} 
ante el miedo común a “lo popular” y muy especialmente cuando ese ente para ellas inquietante ha adquirido carácter de combatividad socialista (en su forma organizada marxista) (Marini, 1978).

Las respuestas populares, que aglutinan a amplios sectores del Trabajo, no se hacen esperar, en forma de organizaciones políticas y militares y el desatamiento de guerrillas, de marcado corte leninista o maoísta en uno u otro caso, en un subcontinente que cuenta con una larga, profundamente arraigada e intensa lucha popular armada que llega hasta hoy mismo ${ }^{31}$. El objetivo predominante es la segunda descolonización, hasta el logro de sociedades que comiencen a construir el socialismo. Para ello se contempla como ineludible la toma del poder político. Los sujetos colectivos con carácter transformador en ese contesto geopolítico e histórico son predominantemente sujetos armados.

Por su parte, las nuevas periferias de África, Asia y Pacífico, adquieren su “independencia” bajo la orientación del desarrollismo-populismo. En ellas se han producido movimientos de liberación-independencia que intentan una primera descolonización (o independencia formal política), e incluso en algunos casos la segunda independencia (la económica, en un intento de quemar al unísono todas las etapas). A menudo están inspirados por la revolución soviética, ya sea dirigidos por el partido único (China) o en coalición (Argelia). Al final del ciclo emprenden este proceso otros países africanos como Angola, Mozambique, Cabo Verde o Guinea Bissau,

\footnotetext{
${ }^{31}$ Aquí las expresiones del Trabajo como sujeto han combinado en un relativamente breve lapsus las formas ofensiva y burocratizada propias del Capitalismo Liberal Competitivo (CLC) y del Capitalismo Monopolista de Estado (CME) de las sociedades centrales. Al tiempo, comienzan a manifestarse nuevas formas de la lucha de clase en su expresión indígena y campesina (o indígeno-campesina), contra la usurpación de tierras, desalojos, atropellos y su humillación como fuerza de trabajo y como seres humanos ajenos a cualquier consideración de "ciudadanía”. Se están gestando los embriones de lo que más tarde serán nuevos sujetos indígenas, y se forzarán, como intentos de prevención, contención o asimilación de los mismos, las políticas indigenistas de diferentes Estados americanos. Ante la imposibilidad de la importación de la "paz keynesiana", se produce a partir de la mitad del siglo XX una proliferación de las expresiones armadas del Trabajo, en forma de guerrillas, Frentes, Ejércitos del Pueblo, comandos urbanos, etc.; esta vez ya con el referente de la revolución cubana, triunfante cuando finalizaba la década de los 50. Plantean la toma del poder institucional mediante vías o estrategias como el foquismo (predominantemente militar), la guerra popular prolongada (militar con trabajo político comunitario), la vía proletaria (predominantemente política, con apoyo de la lucha armada), o la tercerista (levantamiento insurreccional masivo, pero como fruto de la previa penetración política de la población). A caballo entre el CME y su rompimiento en forma de Capital global va cobrando vida palpable el indianismo como proyecto político autónomo de los sujetos indígenas, que desafía su integración en la sociedad dominante y recupera al menos en parte la clave histórica de su lucha: ser más allá del mundo capitalista. Generadores de su propio discurso, los sujetos indígenas reintroducirán el elemento étnico (que se pretendía disuelto) en la lucha de clase. Si bien es cierto también que a menudo desconsideran que son parte del tablero de la lucha de clase.
} 
fruto de la tardía descolonización portuguesa. Representan una nueva versión: la de los movimientos político-militares frentistas.

Se forma también el Movimiento de los No Alineados (Bandung Indonesia-, 1955) por países y líderes que irrumpían a una pretendida "tercera vía”, y cuya propuesta era que el desarrollo es posible desde el no alineamiento a un bloque político-militar ni la imitación ciega de modelos (se intenta una reorganización social trastocando ciertas formas de dominio tradicional, al tiempo que se ponen en escena políticas «nacionalistas», para la atención de la demanda, etc.).

Pero sea bajo unas u otras coberturas, la superexplotación es la versión dominante del capitalismo dependiente o periférico. Explotación extensiva de la fuerza de trabajo frente a la explotación intensiva que gana más y más terreno en las sociedades centrales (y que indica el aumento de la productividad del trabajo o fase de alza en el ciclo de acumulación) ${ }^{32}$.

El cierre de este modelo en las sociedades centrales viene de la mano de un conjunto de circunstancias coincidentes, como son la caída de la tasa de ganancia por el incremento de la composición orgánica del capital; el aumento del poder social de negociación del Trabajo y con él su capacidad para obtener más parte del total de la plusvalía generada; el aumento también de su capacidad de frenar la intensidad en el trabajo (menos trabajo, mejores condiciones laborales, menor intensidad laboral). Además, el incremento de la renta de los asalariados exigía una mayor diversificación del consumo, debilitando el rígido esquema fordista de producción.

Por último, la Tercera Revolución Tecnológica se había generalizado, pasando de ser una fuente de beneficios a una causa de sobreproducción y aumento de la competencia. La consiguiente falta de rentabilidad desincentivaría la producción.

Ante esta situación, los tradicionales mecanismos anticíclicos keynesianos pierden su utilidad. Si antes el crecimiento salarial fortalecía la demanda, ahora interfiere en los beneficios; si antes la expansión expandía el empleo, ahora hay que reestructurar el aparato productivo a costa de las plantillas y facilitar la flexibilidad contratadora; si antes los gastos del Estado habían ayudado a contar con una demanda relativamente fuerte, ahora debían reorientarse para favorecer la inversión y acrecentar la tasa de

\footnotetext{
${ }^{32}$ La explotación extensiva se realiza a través de tres procedimientos: a) por aumento de la duración de la jornada de trabajo; b) por el incremento de la intensidad del trabajo sin elevación equivalente del salario; c) por la reducción del fondo de consumo del trabajador (Marini -1985-, Martins -2000-). El capitalismo dependiente combinará estas tres expresiones de la explotación extensiva, mientras que en su conjunto el capitalismo histórico ha ido configurando un sistema articulado de relaciones de producción capitalistas, semicapitalistas y precapitalistas, vinculadas entre sí por relaciones capitalistas de intercambio y dominadas por el mercado mundial capitalista (Mandel, 1979:49), que, como anticipara Trotsky, dan origen a un desarrollo desigual y combinado de las diferentes formaciones sociales.
} 
ganancia capitalista, reduciendo aquellos gastos también mediante el recorte de impuestos sobre el excedente (Albarracín y Montes, 1996). Todo lo cual abre la puerta a las iniciativas de represión de la demanda y regresión fiscal, combinadas con políticas recesivas y de control del déficit y de la inflación, que presidirán en adelante por doquier las estrategias de gobierno del Capital.

Para encastar todo ello de forma más o menos coherente había que buscar un nuevo modelo de acumulación que significara una ruptura de los pactos de clase en las sociedades centrales, y se amparara en una nueva doctrina políticoeconómica con graves repercusiones sociales. Esa doctrina sería el neoliberalismo ${ }^{33}$.

5. El actual modelo globalizador es el propio de la fase transnacional del Capital Monopolista, y se basa ante todo en una reestructuración del poder de clase u ofensiva general del Capital (coordinado en gran medida por primera vez como sujeto a escala global a pesar de que acentúe también la competencia entre sí) económica, política y militar, para recuperar tanto su tasa de ganancia como parte de su perdida capacidad de disciplinamiento del Trabajo. En ese proceso el Capital rompe las barreras estatales de regulación social de la producción y de la distribución en que se hallaba relativamente confinado en la anterior expresión de capitalismo monopolista de Estado, y tiende a buscar el espacio global, aunque necesite del Estado para su reproducción y expansión (con lo que se recrudece el papel del mismo como garante de la oferta, y por tanto como represor del Trabajo: esto es, acentúa de nuevo su carácter de clase -abriendo con ello posibles fisuras de cara a su legitimación a corto plazo-).

Esto quiere decir que el "pacto de clase» keynesiano deja de tener valor para el Capital, por lo que en adelante éste emprende un modelo de desregulación social (o regulación unilateral, realizada en exclusiva por él a través del Mercado y el Estado neoliberal), que conlleva consustancialmente la institucionalización de la precariedad y el miedo laboral (Bourdieu, 2001), o lo que se ha llamado también "economía política de la inseguridad" (Beck, 2002). En su primera subfase (hasta los años 90 del siglo XX) se consolida la explotación cualitativa o implicación del Trabajo en su propia explotación y su autocontrol a través de labores rotativas y en equipos por objetivos (toyotismo), que se combinará con expresiones de un "fordismo disperso" que cobijan formas tyloristas y pretyloristas de organización de los procesos productivos, trasluciendo una combinación generalizada de logro de plusvalía absoluta y relativa y la maximización de la subordinación del conocimiento a la forma de dominación sociolaboral.

${ }^{33}$ Una vez mostrado su fracaso histórico, sin embargo, esta nueva irrupción del liberalismo no podría calcar la política del Capital anterior a la constitución del Trabajo como sujeto histórico, ni la previa a la de regulación sistémica por parte del Estado. Aprovecharía más bien el remanente del Estado keynesiano simplemente para favorecer ante todo el lado de la oferta, es decir, el del propio Capital. Para ello se valdrá de su transnacionalización o, podría decirse también, de la mundialización de su ley del valor. 
La Política con mayúsculas, al interior de los Estados, como lugar donde se construye, decide y regula el devenir social y las posibilidades de participación y protagonismo de unos u otros seres humanos o sectores sociales en el mismo, va cediendo más y más terreno a la gestión administrativa, la "administración de las cosas” y la "ingeniería social”34.

Esto no quiere decir que los Gobiernos locales (o el Estado) dejen de tener importancia, como afirman tantos destacados teóricos de la "globalización”, sino que gobernar (regular socialmente) a escala local pierde importancia para el Capital, en virtud de la "regulación mercantil", con lo que aquél destruye espacios democráticos o los desprovee de sustancia práctica (los Estados, como se ha dicho, se centrarán ahora sobre todo en el control de la demanda, aunque por mor de su atolladero de sobreproducción continúen viéndose forzados a recurrir -a la baja- a ciertos dispositivos keynesianos).

El Estado como capitalista colectivo, eje de la dinámica de acumulación "nacional” del Capital, sobrevive más o menos indemne sólo en sus expresiones más fuertes, mientras que las restantes intentan dar paso a formas supraestatales de coordinación (el Macro-Estado o el Estado-Región), más acordes con la fase de acumulación "transnacional” del Capital que ya ha conformado un Sistema Mundial ${ }^{35}$.

La universalización de la ley del valor del capital termina de completarse con la incorporación de la última frontera: la población y recursos del Segundo Mundo (especialmente China, además de la URSS y otros países del Este europeo, pero también de otras zonas de Asia, antes sólo parcialmente incorporadas, y ciertas de África); así como la fuerza de trabajo femenina mundial no incorporada anteriormente (sobre todo de las Periferias del Sistema). Población, en su conjunto, que es integrada con bajos o muy bajos derechos sociales y laborales que pudieran permitir atenuar su extra-explotación. Circunstancia que conlleva la pérdida de poder negociador del resto de la fuerza de trabajo mundial y el refuerzo de la capacidad de dominación de la misma por parte del Capital, con el consiguiente incremento general de la plusvalía (mundial) y la proliferación de formas tyloristas y pretyloristas de (sobre)explotación del Trabajo, que se complementan con formas de neoservidumbre y neoesclavismo.

La última revolución tecnológica en que se sustenta esta expansión mundial y mundializadora del capital se basa en las tecnologías de la

\footnotetext{
${ }^{34}$ Con la agudización de la división social del trabajo, se produce también la acentuación de la profesionalización de la política así entendida, fuera del ámbito de intervención e incluso de comprensión (y con ello del interés) de la gran mayoría de los ciudadanos, que delegan cada vez más en "profesionales" los destinos individuales y por supuesto, por tanto, el colectivo.

${ }^{35}$ Aun así la gran contradicción actual del Capital radica en su necesidad y a la vez su imposibilidad de conseguir un ente regulador universal de su acumulación planetaria, una suerte de Estado global capaz de encauzar la creciente rivalidad intercapitalista.
} 
microelectrónica, la biogenética y la robótica. El intento de rebajar la composición orgánica del capital (del capital fijo, en este caso) introducirá la sofwetización como elemento punta de la industria en las sociedades centrales más poderosas, al tiempo que se produce un desplazamiento productivo a las periferias (a las que se lleva las fases productivas que requieren menor incorporación tecnológica). Con esto se da una reestructuración de las relaciones centros-periferias y ciertos trastocamientos en la división internacional del trabajo ${ }^{36}$.

Hasta ahora la inclinación “pos-industrial” o “post-material” de buena parte de las sociedades centrales ha conseguido sacar ventaja también de la plusvalía físicamente producida en las periferias, a través del aprovechamiento de la brecha en el costo de producción proveniente de una fuerza de trabajo más barata, las economías de escala y el control de la tecnología punta (lo que permite al capital transferido allí vender más barato que los competidores y al tiempo extraer alta plusvalía; plusvalía que también es “captada” tanto de los centros como de las periferias a través del dominio de la infraestructura financiera internacional). Se aumenta así el carácter parasitario de esas sociedades parejo a la simultánea aceleración y redistribución de las fuerzas productivas globales ${ }^{37}$.

Al mismo tiempo el Capital pone en marcha todo un conjunto de dispositivos económicos para relanzar la tasa de ganancia:

- Recurso a mecanismos impulsores al máximo de la utilización decreciente de las mercancías ("fechas de vencimiento" arbitrarias de ciertos productos, como los alimenticios, y obsolescencia programada de otros). Expansión del complejo industrial-militar para sustraer cada vez más producción del mercado (el Estado es un comprador seguro), fuente de continua inflación, lo que termina realizando la identificación del consumo (de la mercancía producida) con la destrucción.

- Crece el porcentaje de subutilización crónica y el acortamiento artificial del ciclo de amortización de las maquinarias e instalaciones. Fiebre de la “innovación” y consiguiente “renovación tecnológica”, atendiendo a las necesidades de la competencia en el mercado, más que a las necesidades reales de la población.

\footnotetext{
${ }^{36}$ Algunas de las sociedades periféricas, aplicando políticas contrarias a lo estipulado por los cánones desarrollistas y aprovechando la reestructuración de la división internacional del trabajo, han logrado convertirse en economías productivas de gran importancia. Cuando cuentan con una dimensión territorial continental o pseudocontinental, como es el caso de China, o en menor medida India o Brasil, pueden llegar a erigirse en rivales de consideración para las sociedades centrales.

${ }^{37}$ Es decir, que en buena parte el capital financiero(-especulativo) de las sociedades centrales "parasita" al capital productivo cada vez más trasladado a las periferias del Sistema. Pero al mismo tiempo, las principales economías productivas periféricas, en razón de su escasa demanda interna resultante de su crecimiento tremendamente desigual dependen sobremanera de la exportación (más de la mitad de la economía china, p.e.), por lo que deben insuflar dinero al sistema financiero de las sociedades centrales (especialmente a Estados Unidos) para que les puedan seguir comprando.
} 
- Una parte creciente del trabajo vivo se torna fuerza de trabajo superflua, desechada como no explotada y a menudo no explotable. Crece la proletarización de la población mundial, sin que esto signifique pasar por la relación formal de asalarización.

En resumen, que según se agota así la capacidad del capitalismo de desarrollar fuerzas productivas y comienza la contrabalanza a favor de la promoción de fuerzas destructivas, se acentúan los siguientes procesos concomitantes:

1. Uso intensivo de la naturaleza. Creciente depredación de recursos.

2. Uso intensivo de capital en procesos de creación destructiva, acortando la vida de los bienes de consumo y los bienes de equipo.

3. Expansión del valor de cambio, cada vez más contradictorio con los valores de uso (es decir, con las necesidades humanas).

4. Generación masiva de "personas superfluas", o desestimación de cada vez más seres humanos para los procesos productivos. [Berterretche, 2009].

Este nuevo modelo de acumulación combina al mismo tiempo un:

- desplazamiento espacial del capital (hacia las periferias menos conflictivas, con posibilidades de rentabilizar inversiones);

- desplazamiento de producción (hacia el software y nueva línea productiva de servicios, servicios terciarios y cuaternarios...);

- desplazamiento técnico-organizativo (fordismo disperso-" ‘toyotismo cicatero" -sin garantía del puesto de trabajo- Silver -2005-);

- desplazamiento de la producción hacia las finanzas (segunda fase de financiarización universal) ${ }^{38}$.

Todo ello adobado con una lucha contra las conquistas del Trabajo en todos los frentes (que ha tenido su mayor expresión en la destrucción del contrapoder sindical), en la que se evidencia un claro componente de venganza de clase: que nunca más el Trabajo se convierta en sujeto con capa-

\footnotetext{
${ }^{38}$ La posibilidad del desplazamiento temporal del capital excedente también es siempre recurrida, por supuesto, y consiste en que los flujos de capital se alejen del terreno de la producción y el consumo inmediatos (circuito primario de la economía), para invertir en infraestructura productiva a ser rentabilizada en un futuro más o menos lejano (circuito secundario de la economía: instalaciones, capacidad de generación de nueva energía, nuevas vías para el traslado de mercancías y fuerza de trabajo, etc.), o bien en gasto social que favorezca la investigación y el desarrollo y, en general, la cualificación de la fuerza de trabajo en el porvenir (circuito terciario de la economía). No obstante, la inmediatez y cortoplacismo del "interés" de los diferentes capitalistas, nunca les permitió terminar de apostar abiertamente por este desplazamiento temporal de la ganancia, por lo que tuvieron que recibir el "empujón” de la lucha de clase que posibilitó que el Estado (como "capital colectivo") asumiera esas tareas con muy diferente entusiasmo en unas y otras sociedades. Hoy, dados los crecientes problemas de rentabilidad y la escasa dimensión de esta lucha en tantos lugares, el Capital se inclina en proporción decreciente por esta salida (enflaqueciendo las posibilidades del Estado en este sentido).
} 
cidad de poner trabas estratégicas a la acumulación de capital. Se trata, en definitiva, de modificar de modo duradero las relaciones de fuerza entre las clases, y de institucionalizar esa modificación.

Harvey (2007a) ha señalado 3 grandes vertientes de la ofensiva del Capital en esta fase, que marcan los componentes de la desposesión universal de la humanidad convertida toda en Trabajo:

1. Por privatizaciones o apropiación de la riqueza social [con su cadena de secuelas: apropiación de tierras y el consiguiente desplazamientos de poblaciones campesinas; desaparecen formas de producción y consumo precapitalistas y no capitalistas; eliminación de propiedades comunales o colectivas; monetarización de las relaciones sociales y humanas; mercantilización de los recursos genéticos; sustitución de la agricultura campesina o familiar por agroindustrias; universalización de la proletarización, a menudo sin asalarización; derechos de propiedad intelectual o patentes sobre recursos ajenos; obtención de recursos y materias primas baratas; esquilmación de la riqueza cultural y natural de los pueblos.... $]^{39}$.

2. Por esquilmación del ecosistema [acortamiento del tiempo de vida media de los productos; mercantilización de la naturaleza en todas sus formas (drástica disminución de los recursos disponibles); empresarización y privatización de instituciones públicas (como las universidades); apropiación militar directa de los recursos y materias primas más codiciados...]

3. Por devaluación de los activos existentes de capital y trabajo a través del sistema financiero y las instituciones de crédito [promociones fraudulentas de títulos; destrucción deliberada de activos mediante la inflación y a través de fusiones y absorciones; endeudamiento generalizado (por encima de la capacidad de pago) y consecuentes disciplinamiento y servidumbre por deudas; fraudes empresariales; desposesión de activos mediante la manipulación del crédito y las cotizaciones (p.e. el saqueo de los fondos de pensiones); ofensiva especulativa de los fondos de riesgo ("hedge funds")...].

A ello se suman las políticas conservadoras expandidas al conjunto de sociedades a partir de la ofensiva Reagan-Tatcher, con la reducción de aportes patronales a la seguridad social, las reformas tributarias regresivas, el incremento de las oportunidades de inversión del capital excedente a través de privatizaciones masivas, la legalización de trabajos precarizados y el descenso de los salarios públicos, entre otras medidas dirigidas a recomponer el poder de clase ${ }^{40}$.

\footnotetext{
${ }^{39}$ El conjunto de estas circunstancias constituye lo que Amin (2007) ha llamado prosecución de "enclosurs planetarios", sin absorción asalariada del campesinado desposeído.

${ }^{40}$ Esta impuesta reducción de la diversidad en términos ideológico-regulativos para afrontar la acumulación capitalista en las diferentes formaciones sociales, fue bautizada como
} 
Se generó con todo ello una extendida pérdida de capacidad del Trabajo para asegurarse su propia reproducción, con la consiguiente eclosión migratoria, que ha propiciado al tardocapitalismo un enorme ejército de reserva, ya a escala planetaria, con el que socavar por doquier las conquistas del Trabajo.

Por su parte, la gobernanza o gobernabilidad (que para algunos autores es la clave de este modelo de acumulación) significa que todo esto se pueda hacer sin la insubordinación del Trabajo, gracias a la acentuación de los dispositivos de coacción político-judicial y al incremento de la represión policíaca a nivel intraestatal e interestatal, así como de la represión militar a escala global (esta última a través de una guerra permanente o guerra difusa -que hay quien ha llamado "guerra civil contra la humanidad"-, y que pretende ser legitimada como "guerra al terrorismo" -monopolio universal de la violencia: violencia sustancia de la acumulación-).

El Capital cuenta para ello también con el monopolio de los dispositivos de socialización reglada y un control mediático sin precedentes, reforzado por los procesos de oligopolización de los media, por los que el hardware y el software pasan a ser de una misma propiedad (los detentadores de los medios de producción anexionan los medios de difusión masiva, formando grandes conglomerados de poder económico-político). Su más importante papel consiste, probablemente, en propagar la naturalización de la desigualdad y la injusticia.

El entramado de procesos, políticas y estrategias descrito, se aúna para provocar una decadencia del ciclo de luchas del Trabajo (que pasa ahora cuanto mucho a la defensiva de sus conquistas) sin precedentes desde su constitución como sujeto a lo largo de la primera revolución industrial. Se dan también una serie concadenada de resultantes que se retroalimentan con ello: des-socialización de la Política o despolitización del Mundo de la Vida / pérdida de calidad democrática de las sociedades e instituciones (tendencia a instancias de gobierno y decisión supraestatales al margen de controles democráticos) / desclasación - dilución de la conciencia de clase (justo cuando más se radicaliza para el Capital la conciencia de clase y la ofensiva de clase) / reducción de los sujetos a individuos y éstos convertidos en los únicos agentes sociales (del macrocorporativismo general que implicaba el "Estado Social”, se pasa a un microcorporativismo particularista, en el que cada quien percibe y busca la "salvación” a escala

\footnotetext{
“pensamiento único”. (ver para la génesis y expansión de tales medidas, Harvey -2007b). Sin embargo, actuaron como algo más que "pensamiento", en el sentido de que compelieron al conjunto de capitales mundiales a ir adoptándolas, so pena de perder "competitividad" frente a quienes más destrozos de la condición laboral habían ocasionado (supresión de mecanismos de control sobre la contratación y uso de la fuerza de trabajo; desmantelamiento de los convenios colectivos; destrucción, domesticación o cooptación de las organizaciones sindicales; prolongación del ciclo de la vida laboral; confiscación de derechos laborales universales; aumento del desempleo, fragmentación de los mercados laborales - ver para el significado de esto, Gilly y Roux, 2009).
} 
individual (Alonso, 1999) ${ }^{41}$ / involución en la conquista de derechos / acentuación de la desigualdad social / blindaje de la ciudadanía o reducción de ésta a ciertos sectores sociales...

En esta fase se va a producir el fin del bloque-Segundo Mundo como sujeto internacional; la derrota del proyecto modernizador de las burguesías de nacionalismo desarrollista (o "burguesías compradoras") de las periferias, nacido en Bandung; el agotamiento del proyecto desarrollista en África y Asia ${ }^{42}$, y del Estado populista como remedo del "Social”, en América Latina; así como el desmantelamiento creciente del propio Estado Social, en las sociedades centrales.

Aprovechando estas circunstancias el Capital de las sociedades centrales busca la restauración del patrón colonial de crecimiento, ahora a escala global (planificándola a través del Consenso de Washington ${ }^{43}$ ), inten-

\footnotetext{
${ }^{41}$ La ciencia, cada vez más como factor clave en la reproducción material e ideológica del Capital, se encargará de coadyuvar a este proceso. La Ciencia Social dominante promoverá por todos los medios la "desconstrucción” de los sujetos, proponiéndonos de nuevo la recuperación del individuo, esta vez no tanto "racional” o "económicus”, como inerme o, en la terminología al uso, “postsoberano”. Fomentando con ello las interpretaciones positivistassubjetivistas, fenomenológicas, que toman lo que no son sino resultados de determinados procesos históricos estructurales, por datos o elementos “explicativos” del mundo social (en vez de buscar la explicación de ellos mismos); en donde proliferan por ello descripciones de “subjetividades” y “estilos de vida” sin ningún anclaje estructural. Se toma así el proceso de individuación actual y de preferencia por las opciones privadas, que no son sino el resultado de la reciente guerra de clase y de la continua socavación de las alternativas del Trabajo en el capitalismo histórico de los dos últimos siglos, como características universales y ahistóricas de los seres humanos.
}

${ }^{42}$ Esta es la base de la vuelta a arcaísmos religioso-culturales en numerosas sociedades, como forma de huir del espejismo imitativo de "Occidente". La "desconexión" de buena parte de las sociedades árabes e islámicas, por ejemplo, al margen de la Modernidad, tiene su explicación en el hecho de que en países sin posibilidad de establecer un capitalismo de consumo, las fracciones locales del Capital se valdrán necesariamente de una religión que predica la moderación consumista y la frugalidad de vida para mejor mantener el consentimiento de la dominación de sus poblaciones, eliminando o desplazando a la izquierda organizada de inspiración marxista, o a la de carácter pequeño burgués, nacionalista-desarrollista. La necesidad del Capital Transnacional de entrar también en esos espacios, está detrás de la ofensiva contra esas sociedades (favorecida por el aumento del fundamentalismo católico, en lo que supone un magnífico choque de oscurantismos -más que de “civilizaciones”-). Para el neoliberalismo, la destrucción social y el ultraindividualismo que su propia praxis genera, deben intentar compensarse con la recuperación de formas de creer en la comunidad que mantengan el espejismo de ésta, compensen en parte el retraimiento de lo social y hagan gobernable al conjunto disperso de individuos en que han venido convirtiendo las sociedades. Se revitalizan así religiones, asociacionismos dóciles, fascismos, nacionalismos integrados...

${ }^{43}$ Entre sus principales propuestas: Dado que se parte de que el sector privado gestiona mejor los recursos que el público, los gobiernos deben reducir el peso del Estado y dejar buena parte de los servicios (aunque sean "universales”) en manos del sector privado El Estado debe ser un mero facilitador de este sector (función de estabilidad), al tiempo que un 
tando limitar la capacidad de acción de los Estados periféricos, e incrementando por tanto la distancia centros-periferias y la desigualdad entre países, entre regiones dentro de cada país, entre clases y entre fracciones de clase.

Además, el Capital como sujeto cada vez más consciente y planificador, logra en las últimas décadas la destrucción (en muchos casos física), sometimiento o cooptación (a menudo también por conversión ideológica) de las principales organizaciones y sujetos del Trabajo en todo el planeta (consiguiendo en gran medida la imposición del marco dado de las cosas: “fuera del Sistema no hay nada”). Asimila también las reivindicaciones del Trabajo esparcidas en forma de Nuevos Movimientos Sociales (NMS) a partir de la incorporación parcial y lo más aséptica posible de aquéllas en las diferentes agendas políticas.

Confina, en definitiva, a buena parte de los anteriores grandes sujetos o movimientos del Trabajo, tanto de primera (MO) como de segunda generación (NMS), en esferas cada vez más reducidas, de reivindicaciones autolimitadas y objetivos inmediatos que no contemplan ya casi nunca la universalidad social. Se da así la transformación de aquéllos en microsujetos (o sujetos de tercera generación) que se expresan en agrupaciones de muy reducidas dimensiones, que admiten poca o nula disonancia ideológica, con muy limitado radio de acción e influencia sociopolítica (asociaciones y colectivos de muy diverso tipo, ONGs, comités, micropartidos sin posibilidades electorales, mesas o plataformas muy coyunturales...): son los Nuevos-Nuevos Movimientos Socia$\operatorname{les}^{44}$. Éstos se corresponden con la producción a nivel social de identi-

regulador ocasional de sus excesos (con programas de alivio de la pobreza, p.e.), así como garante de la paz social ("gobernanza”). Como quiera que se propugna que la globalización es beneficiosa para todos los países, la extraversión (y extranjerización) de las economías periféricas lejos de ser un problema, garantizará su capitalización y la incorporación de tecnología. La existencia de "polos de desarrollo" mundiales desencadenará un proceso de “cascada de riqueza”, que derramará al conjunto de la población y de las sociedades (antiguo apotegma de la "Escuela de Chicago").

${ }^{44}$ En este contexto tiene lugar un reflujo de los referentes políticos construidos a lo largo de los dos últimos siglos (como el de clase o género) nuevamente a los de sociedad civil (en su acepción más marcadamente burguesa). En consecuencia se agranda la amorfización y al tiempo atomización de los agentes sociales, cada vez más (auto)confinados en formas asociativas u organizativas más y más pequeñas. Se reclama de nuevo la prioridad del individuo-ciudadano, desasociado (justamente cuando «la ciudadanía» queda fuera del alcance de cada vez más sectores del Trabajo, gracias a su conversión en excluidos -el concepto de “exclusión” diluirá en adelante la conciencia de pauperización provocada por las dinámicas de acentuación de la explotación y expulsión del mercado laboral. La concepción de pobres irá sustituyendo poco a poco a la de proletarios-). Sin proyecto ni fidelidad histórica, los NNMS son cada vez más esporádicos, de militancia crecientemente intermitente o puntual (relacionada a menudo con ciertas formas de amistad, se deshacen por desafecciones internas o bien al conseguir sus objetivos más inmediatos, o ante una elevada adversidad), con bruscos toboganes de concentración y desconcentración de actividad. Producto de la 
dades vaciadas de conflictividad y de direccionalidad (con la consiguiente apología del "multiculturalismo").

La acentuación de la supeditación estratégica del conjunto del Trabajo (único factor capaz de revertir la dinámica autodestructiva del Capital), se correlaciona con la penetración del Capital en todos los aspectos de la Vida social y privada. El conjunto de los seres humanos se convierten en fuente de valor productivo y reproductivo, quedando toda la vida de los mismos sometida a la lógica del valor del Capital. Lo que es igual que decir que, aunque no sea directamente explotada, el conjunto de la humanidad es transformada en Trabajo (y la totalidad de la Vida en valor) ${ }^{45}$.

Pero al llegar a este punto de domino de la Vida, paradójicamente, el capital tropieza en formas ampliada con sus propios límites, al generar al parecer insalvablemente procesos de retroalimentación negativa.

\section{Algunas de los más importantes al acabar el siglo XX eran:}

I. La reestructuración o restauración liberal no pudo aumentar los indicadores de crecimiento.

En los años 60 del siglo XX el crecimiento fue de 3,5 puntos y de 2,5 en los 70 con políticas keynesianas, En los 80 fue de 1,4 y en los 90 de 1,1, con políticas neoliberales (Chesnais, 2008). [De hecho, en plena ofensiva neoliberal de los años 80 las economías centrales que más crecieron fueron las menos neoliberales, véase, Alemania y Japón].

II. Con el desplazamiento espacial y la transnacionalización se agravó la sobreacumulación, creando nuevos centros de manufactura y mecanización mundiales que añadieron un enorme volumen de capacidad productiva al mundo, deprimiendo precios y beneficios.

Las tasas de beneficio de las 500 empresas más importantes de la lista Fortune decrecieron de 7,15 de promedio en los años 60, a 2,29 en los 90 del siglo XX, siendo para los primeros años del siglo XXI (2000 a 2002) de 1,32 (Chesnais, 2008).

III. Con la incorporación del Segundo Mundo no sólo se consigue un único espacio de valor mundial, sino que se duplica también la oferta de trabajo mundial, deprimiendo al tiempo salarios, precios y perspectivas de ganancia. Las recurrentes políticas monetaristas del tardocapitalismo, dirigidas a contener los salarios, no hicieron sino reducir aún más las demandas de la fuerza de trabajo.

implosión de anteriores sujetos sociales y de sus organizaciones, están estrechamente vinculados a las formas oenegeístas de intervención social (ver Piqueras, 2002). Procesos que contribuyen también, en todo el planeta, a la recuperación del protagonismo social de las diferentes Iglesias y sus organizaciones, amén de otras formas asociativas de carácter asistencial, paliativo o caritativo.

${ }^{45}$ Esto quiere decir que se difumina la distinción entre las esferas Productiva y Reproductiva, obteniendo el Capital valor de todo el ciclo de la vida de los individuos (aprovechando no sólo todas sus capacidades, sino también todas sus potencialidades, todas sus posibilidades de ser). 
El Capital vio su más importante opción en la financiarización de la economía ${ }^{46}$.

Así pues, el resultado de la permanente pugna contra la crisis de sobreacumulación que ha venido protagonizando el Capital a través de su expresión dogmática político-económica, el neoliberalismo ${ }^{47}$, ha sido dar unos años más de salida relativamente ficticia a la acumulación, a través de la financiarización económica (acometiendo la $2^{\mathrm{a}}$ fase de financiarización universal -Arrighi, 1999-) y la depresión constante de la demanda. Esto ha conducido a una pauperización relativa también universal y una creciente pauperización absoluta, que al hacerse más y más extensa, ha ido tirando por tierra la panacea liberal de la salida de la crisis mediante el incremento de las exportaciones o a través de la venta incesante de mercancías, marcando un dilema de doble negatividad para el Capital.

Por otra parte, si la incorporación del Segundo Mundo al Sistema Mundial había originado por primera vez un único espacio de valor mundial, éste ha devenido una extremadamente delicada madeja de interconexiones de capitales financieros y productivos entre las economías centrales y las periféricas de alta capacidad productiva, que está reestructurando todo el Sistema y que deja una incógnita muy alta sobre sus vías de continuidad en el siglo XXI ${ }^{48}$. Incógnitas que se multiplican con el fin de la era de la energía barata y el acabamiento de ciertos recursos estratégicos, amén del gran desorden ecológico que amenaza con desestabilizar agudamente la continuidad sistémica.

En un orden diferente, hay que hacer referencia también a la ampliación de la potencialidad "objetiva” de desestabilización por parte del Trabajo, dado que según penetra la dominación del Capital en todos los órdenes de la Vida, más se amplían las posibilidades de socialización del antagonismo de clase, por más que éste no adquiera de momento un carácter

\footnotetext{
${ }^{46}$ En 1979 las operaciones con divisas eran de 17,5 billones de dólares (11 veces el valor total del comercio mundial). En 1984 eran de 35 billones (20 veces el valor total del comercio mundial). En 1982 las inversiones mundiales fueron de 2,9 billones de \$. En 2004 ascendieron a 9 billones \$ (+ 5,3\%). Los activos financieros mundiales en 1982 eran 13,9 billones de \$. En 2004 ascendieron a 148,6 billones (+11,45\%). El PIB mundial era en 1982 de 11,1 billones de \$. En 2004 fue de 40,9 billones \$ (3,7 veces menos que activos financieros) (+6,1\%). Esto no quiere decir que sea el capital financiero el que explique al industrial, sino al revés, aunque no podemos entrar aquí en esa explicación.

${ }^{47}$ El llamado neoliberalismo, como se ha apuntado desde la crítica marxista, no ha sido otra cosa que el discurso triunfalista de la degeneración financiera, parasitaria, del capitalismo keynesiano.

${ }^{48}$ De momento, las sociedades centrales se ven forzadas a rehacer la división internacional del trabajo mediante la recomposición de sus sectores industriales sobre otras bases, utilizando en casa la fuerza de trabajo formada en las periferias o incorporando a éstas en esferas regionales de influencia (de lo que la UE constituye un destacado ejemplo), aunque esto sólo se pueda realizar a través de más proteccionismo interno y expansionismo transnacional de corte imperialista.
} 
manifiesto (el antagonismo latente se expresa de momento, como se ha dicho, en una lucha de clase cuantitativa -ver nota 10-). Las posibilidades de que esos antagonismos se expliciten y se retroalimenten positivamente con nuevas formas de conciencia antagónica dependerán en buena medida del decurso de otras contradicciones, con las que son susceptibles de reforzarse o debilitarse.

En cualquier caso, el conjunto de límites que evidenció el capitalismo monopolista transnacional a lo largo de los años 90 del siglo XX acabó con el espejismo de la “mundialización feliz” (Fernández Durán, 2003) dando paso a una subfase de reacomodo.

Efectivamente, en la segunda mitad de los años 90 del siglo XX el Consenso de Washington conocerá cierta marcha atrás, consecuente con la rectificación del curso ultraneoliberal (o reacomodo liberal-keynesiano) que se produce a partir de entonces y que se corresponde también con la decadencia económico-política del hegemón de la segunda mitad del siglo XX: EE.UU. (este último factor introducirá también la incertidumbre en la dinámica de acumulación capitalista a escala planetaria, la cual durante medio siglo se había visto libre de conflictos interimperialistas).

Tal "rectificación” se produce en medio de sucesivas crisis estructurales: crisis energética-ecológica (la cual establece unos inobviables límites infraestructurales a la dinámica de reproducción ampliada del capital y en lo inmediato conlleva, entre otras muchas drásticas consecuencias, el profundo cuestionamiento del crecimiento como posibilidad, como leit motiv y como paradigma del Sistema, junto a la creciente certeza de que en adelante la acumulación tendrá que efectuarse de forma cada vez más exclusiva y excluyente y su “efecto riqueza” repercutir en cada vez más exiguas minorías); crisis de la división internacional del trabajo; aumento de la inestabilidad mundial (nueva carrera armamentística nuclear, creciente militarización de las relaciones internacionales, desafío de la hegemonía estadounidense); cada vez más frecuentes cortocircuitos de sobreacumulación, que combinados con el aumento de la "economía ficticia”, apuntan a serios obstáculos en la propia dinámica interna de acumulación. Probable crisis civilizacional como sumatorio de todas las crisis $^{49}$.

Estos dilemas infraestructurales y estructurales intrínsecos a la propia dinámica de acumulación capitalista, se combinan con otros que en

\footnotetext{
${ }^{49}$ Estas circunstancias han hecho resurgir la polémica sobre las ondas, dado que según algunas interpretaciones el último modelo de acumulación capitalista habría puesto en entredicho la dinámica histórica de aquéllas, por lo que hace a su duración, rompiendo con la presunta rigidez de su formulación. Según este punto de vista, estaríamos anclados en una fase B recesiva de forma crónica desde los años 70 (no se trataría de una crisis cíclica sino permanente). Sin embargo otros autores defienden que el Capital emprendió una recuperación ascendente de la tasa de ganancia a mediados de la década de los 90, todavía no interrumpida a pesar del desatamiento de cierta “crisis” de choque en 2009. Lo que pasa es que la acumulación se realizaría ahora de forma más oligopolista.
} 
principio favorecen la capacidad antagonista del Trabajo, como son:

1. La tendencia creciente a la socialización de la producción

2. A medio plazo la drástica reducción del ejército de reserva mundial con el agotamiento de nuevas poblaciones por ser proletarizadas (y utilizadas para presionar a la baja los logros alcanzados por las ya proletarizadas)

3. La mundialización capitalista pone al alcance por vez primera la posibilidad real de intercomunicación global del Trabajo y de planificación conjunta de la alternatividad.

Resultaría previsible que merced a los sucesivos desplazamientos espaciales o espaciotemporales de capital, los conflictos laborales también se desplacen a los nuevos centros de industrialización, como ocurrió en el pasado (Silver, 2005), acuñando nuevas formas de enfrentamiento y probablemente también, de organización. ¿Ocurrirá lo mismo con las nuevas expresiones industriales o "postindustriales" de la economía en las sociedades centrales? ¿Coincidirán las nuevas formas de insubordinación desencadenadas por el despojo con las que suscita la sobreexplotación? ¿Se inaugurará una nueva ola de conflictos en la transición de hegemonías que depara el Sistema Mundial capitalista? ${ }^{50}$ ¿confluirán por fin las diferentes identidades precapitalistas y las que han irrumpido de las fracturas al interior del propio Trabajo (como las de género), en un reforzamiento mutuo con las identidades de clase?

De momento las dificultades de articular la enorme heterogeneidad de situaciones e intereses que comprende la condición de Trabajo tanto a escala intraestatal como, aún más, interestatal, se suman al enorme y puede que creciente desfase en la organización y coordinación del Trabajo respecto al capital mundializado. Pero si las fuerzas el Trabajo van a tener algún protagonismo en el futuro inmediato, están obligadas a inventar nuevas estrategias y proyecciones organizativas a escala del capital transnacional ${ }^{51}$.

\footnotetext{
${ }^{50}$ Arrighi y Silver (1999) señalan que el incremento de la proletarización mundial, de la feminización, la cambiante configuración espacial y étnica de las fuerzas de trabajo y la imposibilidad de combinar la satisfacción de las demandas de la misma en los centros y en las periferias del Sistema, el abandono de los intentos por ampliar las bases sociales de la hegemonía en todo el mundo, el aumento grotesco de la polarización en la concentración de las oportunidades de vida y el descarte de los pactos desarrollistas Capital/Trabajo a escala planetaria, son proclives a provocar una irrupción del Trabajo más virulenta que en los anteriores cambios de hegemonía.

${ }^{51}$ Como dice Tilly (1995), si el mundo del trabajo quiere conseguir nuevos derechos colectivos o al menos mantener los que fueron conquistados, debe dejar de referirse o autolimitarse a la dimensión estatal, toda vez que el Estado ya no es el agente regulador básico. Hasta ahora las formas de lucha que afloran del antagonismo latente a un nivel más vasto adquieren expresiones acordes con el capitalismo tardío o senil ("informacional”) en el que nacen, con formas organizativas virtuales, reticulares (tras la descomposición de las formas físicas de reunión y organización tradicionales). De ahí la prevalencia actual de los "arcoiris", "rizomas”, "redes”, “webs”... Formas de organización muy blanda, muy flexible, con relati-
} 
En términos planetarios, el gran déficit o carencia de los esfuerzos de la Vida por irrumpir ofensivamente en el orden del Capital es la ausencia de expresiones organizadas que coordinen o (re)construyan sujetos con estrategias y proyectos de sociedad propios. Y con ello, la carencia de direccionalidad de las luchas, que implica una ausencia de alternativas sólidas, creíbles, de carácter universal. Pesa como una losa para las posibilidades de transformación social la orfandad de una (re)construcción proyectiva como la que inspiró el socialismo.

La redefinición o reconstrucción de ese proyecto se convierte, por tanto, en elemento clave para las reducidas y fraccionadas "vanguardias" del Trabajo en la actualidad.

Pero las insuficiencias al respecto son manifiestas. Especialmente porque los terribles retos que enfrenta la humanidad combinan factores ecológicos, demográficos, económicos, sociales, culturales e incluso psicológicos muy difícilmente regulables e igualmente arduos de encajar al unísono en estrategias programáticas que proyecten un posible acontecer postcapitalista. Supone arrancar desde un nuevo consenso en cuestiones como decrecimiento, distribución, descenso demográfico, horizontalidad democrática, democracia económica, eliminación de la construcción de género y de la división sexual del trabajo, solidaridad intergeneracional e intercomunitaria, compromiso colectivo, responsabilidad con la vida, igualdad, etc., a las cuales hasta ahora la nueva teorización socialista (o del "socialismo del siglo XXI”) ha dado sólo muy parciales respuestas.

¿Quiénes pueden ser los sujetos históricos encargados de la Gran Transformación hacia el postcapitalismo ${ }^{52}$ Esta es probablemente la matriz de todas las preguntas en este sentido, y las posibilidades de respuesta

vamente escasa operatividad y constancia, por el momento. Lejos todavía de poder afectar la esfera productiva, ni apenas ya la circulatoria (salvo en los casos más combativos en las sociedades periféricas, que atentan a menudo contra la realización de la plusvalía -cortes de rutas, 'puebladas', plantones en las ciudades, etc.- ya que no contra la generación de la misma -Lucita, 2001-), su intervención está orientada a trabar el orden dado de las cosas (bloqueo de cumbres o de reuniones del Capital, actos de disidencia, desobediencia, protesta, de visibilización de injusticias, de puesta de relieve de las consecuencias depredadoras del Sistema, etc.) [Para abundar sobre estos puntos, Piqueras (2002)].

${ }^{52} \mathrm{Si}$ en un principio fueron los artesanos y obreros especializados los que resultaron desplazados por trabajadores descualificados industriales que protagonizaron reivindicaciones de clase ("combatividad marxista”) frente a las aspiraciones corporativistas de los primeros (“combatividad polanyana”), más tarde fue el "obrero-masa” de la cadena de montaje fordistakeynesiana quien dio paso por arriba a profesionales con una amplia banda de cualificaciones (ciertos sectores de los cuales reaccionaron contra las consecuencias más negativas del productivismo-consumismo capitalista en la esfera de la circulación, dando vida a los NMS), mientras que por abajo aquellos prototipos del Trabajo se vieron desbordados por una nueva ola de proletarización sin regulación keynesiana en las sociedades centrales y por una fuerza de trabajo migrante global en permanente disponibilidad, proveniente de la extensión de los procesos de proletarización de las periferias (en ambos casos afectando en mayor 
se antojan tanto más complicadas cuanto que la urgencia de las claves ecológicas nos deja muy poco margen temporal para esa transformación. Más difícil aún si consideramos que la conciencia requiere normalmente de tempos largos.

Sin embargo, todo indica que el futuro inmediato no va a ser precisamente de "normalidad", con lo que las retroalimentaciones materialidadinmaterialidad pueden ciertamente acelerarse y, en este sentido, la flexibilidad y capacidad de adaptación de la humanidad a lo largo de su periplo por el planeta la dotan de un potencial previo no desdeñable. Es muy probable que si la especie sapiens-sapiens va a sobrevivir algo más de tiempo será debido a que las fuerzas del Trabajo habrán encontrado la forma de reconstituirse, no para empezar de la nada, sino para aprovechar mejor lo ya hecho y desafiar eficazmente la suicida racionalidad del Capital a través de relaciones sociales de producción razonables.

Los artículos que están incluídos en el Lente de Aproximación de este número constituyen un intento de aportar munición a la imprescindible praxis colectiva que requerimos al respecto.

medida a las mujeres), que provocaron de nuevo reacciones "defensivas" de tipo corporativo-identitario en los primeros, mientras que no han generado todavía en los segundos (debido a su sustituibilidad y debilidad estructurales) reacciones reivindicativas de clase similares a las de fases anteriores del capitalismo. Su creciente importancia para la acumulación capitalista, sin embargo, junto a la también creciente proletarización de los profesionales cualificados, abre claves para comenzar a desentrañar las posibilidades de nuevas irrupciones del Trabajo. En un momento en que las formas de proletarización sin asalarización se combinan también con formas industriales tardías y postindustriales de servicios, que originan en consecuencia muy diferentes formas de ser "proletario", las posibilidades del Trabajo de volver a ser un sujeto histórico pasan por la articulación estratégica de todas las luchas latentes y explícitas (cuantitativas y cualitativas) que en unos y otros tipos de proletarización se generan. Pero en ese sentido no olvidemos que conocer las nuevas composiciones tecnológico-organizativas de las relaciones de dominación de clase, es paso imprescindible para desbrozar los caminos de la subversión. 


\section{Bibliografía}

Albarracín, Jesús y Montes, Pedro (1996), “El capitalismo tardío: la interpretación de Ernest Mandel del capitalismo contemporáneo”, en www.daniloalba.blogspot.com

Alonso, Luis Enrique (1999), Trabajo y ciudadanía. Estudios sobre la crisis de la sociedad salarial. Trotta. Madrid.

Amin, Samir (2007), Por la Quinta Internacional. El Viejo Topo. Barcelona.

Arrighi, Giovanni (1999), El largo siglo XX. Akal. Madrid.

Arrighi, Giovanni y Silver, Beverly (1999), “Hegemonic Transitions: Past and Present”, en Political Power and Social Theory, n 13, pp.239-275.

Beck, Ulrich (2002), La sociedad del riesgo global. Siglo XXI. Madrid.

Berterretche, Juan Luis (2009), “De la gran quema de capital ficticio a la depresión”, en http://correosemanal.blogspot.com/2009/02/de-la-gran-quema-de-capital-ficticio-la.html.

Bihr, Alain (2006), La préhistoire du capital. Le devenir-monde du capitalisme. Page Deux. Lausanne.

Bourdieu, Pierre (2001), Contrafuegos 2. Por un movimiento social europeo. Anagrama. Barcelona.

Brenner, Robert (2006), The economics of global turbulence: the advanced capitalist economies from Long Boom to Long Downturn, 1945-2005. Verso. New York.

Chesnais, François (2008), “El fin de un ciclo. Alcance y rumbo de la crisis financiera”, en Herramienta, $\mathrm{n}^{\circ} 37$. Buenos Aires.

Dierckxsens, Wim (2003), El ocaso del capitalismo y la utopía reencontrada. DEI- Ediciones Desde Abajo. Bogotá.

Dockès, Pièrre y Rosier, Bernard (1983), Rythmes économiques. Crises et changement social, une perspective historique. La Découverte. Paris.

Domènech, Antoni (2004), El eclipse de la fraternidad. Crítica. Barcelona.

Eley, Geoff (2003), Historia de la izquierda en Europa 1850-2000. Crítica. Barcelona.

Fernández Durán, Ramón (2003), “El fin de la ‘globalización feliz’: cede el glamour, se extiende la guerra permanente”, en Mientras Tanto, $n^{\circ} 85$, pp. 79-108. Barcelona. 
García, Ernest (1995), El trampolí fàustic. Germania. Alzira.

García-Durán, Raúl (2006), Mercancías, androides o personas. Elementos para la comprensión de la sociedad actual. Tecnos. Madrid.

Gilly, Adolfo y Roux, Rhina (2009), “Capitales, tecnologías y mundos de la vida. El despojo de los cuatro elementos.”, en Herramienta. Buenos Aires.

Harvey, David (2007), El nuevo imperialismo. Akal. Madrid.

Ídem (2007b), Breve historia del neoliberalismo. Akal. Madrid.

Lucita, Eduardo y otros (2001). "Protesta social: viejas y nuevas formas de lucha”, en Cuadernos del Sur, $\mathrm{n}^{\circ}$ 32. Buenos Aires.

Mandel, Ernest (1979), El capitalismo tardío. Ediciones Era. México D.F.

Ídem (1986), Las ondas largas del desarrollo capitalista. La interpretación marxista. Siglo XXI. Madrid.

Marini, Ruy Mauro (1978), “Las razones del neodesarrollismo”, en Revista Mexicana de Sociología, vol.40, nº extraord., pp.57-105.

Idem (1985), Subdesarrollo y Revolución. Siglo XXI. México D.F.

Martins, Carlos Eduardo (2000), “Superexplotación del trabajo y acumulación de capital: reflexiones teórico-metodológicas para una economía política de la dependencia”, en Problemas del Desarrollo, Vol.31, n 123 , pp.33-54. UNAM. México D.F.

Mészáros, István (2003), El siglo XXI ¿'socialismo o barbarie? Herramienta. Buenos Aires.

Núñez, Rafael (1993), Sociedad y política en el siglo XX. Viejos y nuevos movimientos sociales. Síntesis. Madrid.

Piqueras, Andrés (2002), Movimientos sociales y capitalismo. Historia de una mutua influencia. Germania. Alzira.

Ídem (2005), “La mutua conformación del Capital y el Trabajo desde el capitalismo maduro al capitalismo senil, y las formas sociales a que da lugar”, en Polis, vol.4, n²12, pp. 413-446. Universidad Bolivariana. Santiago.

Ídem (2008), “De la colonización al desarrollo. Del paralelo devenir del Sistema Mundial, la desigualdad, el desarrollo y la cooperación”, en Andrés Piqueras (coord.) Desarrollo y cooperación: un análisis crítico. Tirant lo Blanch. Valencia. 
Polis, Revista de la Universidad Bolivariana, Volumen 8, $N^{\circ}$ 24, 2009

Silver, Beverly (2005), Fuerzas de trabajo. Los movimientos obreros y la globalización desde 1870. Akal. Madrid.

Tilly, Charles (1995), “Globalization Threatens Labor's Rights”, en Internacional Labor and Working-Class History, n 47, pp. 1-23. 